\title{
Las juventudes trabajadoras en el comercio minorista tradicional: gestión, control y resistencias $^{1}$
}

\section{Working youth in traditional retail trade: managment, control and resistances}

\author{
Francisco Nicolás Favieri \\ Universidad Nacional de San Juan, Argentina
}

\begin{abstract}
RESUMEN La flexibilización de las condiciones de trabajo y contratación junto con la aparición de nuevas formas de control y gestión del proceso de trabajo han contribuido a la aparición de nuevas formas de empleo, siendo el sector de servicios y en particular el comercio minorista uno de los que más diversificaciones han presentado en los últimos años. En San Juan, Argentina gran parte de la juventud trabajadora consigue empleos en el comercio, donde además de constituirse como el grupo poblacional que más dificultades tiene para ingresar y permanecer en el mercado laboral se vinculan a la actividad en condiciones precarias de trabajo. Las estrategias y acciones por parte de los trabajadores y las trabajadoras para revertir esas situaciones parecen ser insuficientes, atribuyendo especialmente a las juventudes una posición de pasividad, inactividad y sumisión. A partir de un estudio de caso, este artículo se propone analizar la dinámica del trabajo en el comercio minorista tradicional, caracterizando las formas de gestión y control del trabajo, las expresiones de conflicto laboral y las resistencias emprendidas por jóvenes trabajadores y trabajadoras del Gran San Juan (Argentina) sobre el supuesto de que sostienen una lucha permanente para mejorar sus condiciones de trabajo y que en sus expresiones se configuran nuevas formas de resistencia. Entre los hallazgos
\end{abstract}

1. Este artículo recupera parte del trabajo de investigación realizado para la tesis doctoral "Lidiar con la precariedad" financiado mediante una beca interna doctoral del Consejo Nacional de Investigaciones Científicas y Técnicas (CONICET), Argentina. 
se destaca que las juventudes trabajadoras despliegan diversas estrategias y acciones de resistencia reconfigurando la expresión del conflicto en el trabajo aunque no logran mejorar sus condiciones de empleo.

PALABRAS CLAVE Conflicto laboral; juventud; comercio minorista.

ABSTRACT Flexible working conditions together with new emerging forms of control and management of work process have contributed to the creation of new forms of employment, being service, particularly, retail trade one of the most diversified in recent years. In San Juan, Argentina, a high percentage of young workers are employed in retail trade. Besides the difficulties to entering and keeping in the labour market, this population group have to deal with precarious jobs. The strategies and actions adopted by the workers to change these situations seem to be insufficient, especially when attributing a position of passivity, inactivity and submission to youth. Based on a case study, this article analyses the dynamics of work in the traditional retail trade, characterizing its ways of management and work control, the expressions of labour conflict and the resistance undertaken by young workers from Gran San Juan (Argentina), on the assumption that they are constantly struggling to improve their working conditions and that new forms of resistance are taking shape in their expressions. Among the findings, it is highlighted that working youths deploy various strategies and actions of resistance, reconfiguring the expression of conflict at work, although they are unable to improve their employment conditions.

KEYWORDS Labour disputes; youth; retail trade.

\section{Introducción}

La crisis económica mundial que inicia en los años setenta dio como resultado la adopción de medidas que buscaron sostener la rentabilidad y productividad de las empresas a través de la flexibilización de las condiciones de empleo y contratación y la aplicación de nuevas formas de control y gestión del proceso de trabajo. Estas transformaciones promovieron la aparición cada vez más habitual de situaciones de trabajo con mayores niveles de incertidumbre e inseguridad laboral siendo el sector de servicios, y en particular el comercio, uno de los sectores que más diversificaciones ha experimentado en cuanto a la presencia de nuevas formas de empleo asalariadas precarias incluyendo diversos perfiles de gestión de mano de obra, contratación, disciplinamiento y ritmo laboral (OIT, 2015).

En Argentina como en la provincia de San Juan, el comercio minorista tradicional es una de las actividades que más empleo genera logrando mayor participación 
entre los establecimientos micro, pequeño y mediano empresariales, al tiempo que se constituye como uno de los espacios de empleo comunes entre las juventudes trabajadoras, quienes además, se caracterizan por ser el grupo de población que más dificultades tiene para ingresar y permanecer en el mercado de trabajo exhibiendo en términos comparativos con los adultos, mayor propensión a conseguir un empleo precario (OIT, 2013a).

La literatura científica que aborda temáticas de este rubro, lo hace prolíficamente sobre los sectores súper e hipermercadistas y shopping centers (Abal Medina, 2005; Fernández Milmanda, 2010; Novick, Mazorra y Schlesser, 2008; Radiciotti y D'Urso, 2013), sin embargo, estudios específicos sobre lo que sucede en micro, pequeña y medianas empresas, son escasos y se coloca además como un espacio propicio de indagación (OIT, 2011; Pastrana, Toledo y Villafañe, 2012).

Frente a ese contexto en términos de conflictividad laboral, entre 2016 y 2019, el comercio no se ha caracterizado como un sector particularmente conflictivo para revertir estas situaciones. En San Juan, entre esos años, el comercio representó el 4\% de los conflictos laborales frente al 30\% en enseñanza y el 16\% en industrias manufactureras (GESET, 2020). Las respuestas a esta escaza conflictividad han atribuido responsabilidad a las organizaciones sindicales del sector en relación al modelo sindical vigente, a la fragmentación del colectivo de trabajo (Abal Medina, 2005; 2011; Fernández Milmanda, 2010; Radiciotti y D’Urso, 2013), y en el caso particular de las juventudes a su vinculación inestable con el empleo (Longo, 2016).

Si bien esos hallazgos logran explicar parte de la realidad del sector en términos del conflicto entre capital y trabajo no quiere decir que los trabajadores y las trabajadoras hayan adoptado posiciones de pasividad, inactividad o sumisión. En debate actual desde la Teoría del Proceso de Trabajo (Thompson y Smith, 2009) las nuevas formas de empleo y la aplicación de innovadoras estrategias de control y gestión del trabajo reinsertaron las discusiones en torno a la capacidad de resistencia o disenso sobre el trabajo y se dirigieron a fortalecer la dimensión subjetiva en el análisis de los procesos de trabajo cuestionando la "ausencia del conflicto", es decir, la conflictividad y sus expresiones de resistencia se han reconfigurado y por ello las formas reivindicativas que han caracterizado a gran parte del siglo XX como manifestaciones multitudinarias y/o paros en todos los casos no han logrado el mismo impacto en la actualidad que en el pasado (Soria, 2018). A partir de allí, se han identificado y resignificado las expresiones de resistencia como las de simulación y fuga (Collinson, 2003; Ezzamel y Willmott, 2008; Fleming y Sewell, 2002; Flemming, 2005; Lutgen-Sandvik, 2006) o de apoyo (Cicellin, Pezzillo, Iacono, Berni, Esposito, 2015) ampliando y enriqueciendo los estudios sobre conflictividad en el sector y en ámbitos precarios de trabajo (Bozkurt y Grugulis, 2011) donde también la expresión de las juventudes en esos contextos es revalorizada como activa (Longo, 2016). 
Es por ello que en este artículo nos preguntamos ¿Cómo se configuran los comercios minoristas tradicionales en Gran San Juan? ¿Cuáles son sus mecanismos de control y gestión del trabajo? ¿Cómo se expresan los conflictos en el trabajo? ¿Qué respuestas, en clave de resistencias, despliegan las juventudes trabajadoras? El objetivo consiste en analizar la dinámica del trabajo en el comercio minorista tradicional del Gran San Juan (Argentina) caracterizando las formas de gestión y control del trabajo, las expresiones de conflicto laboral y las resistencias por parte de los jóvenes a partir de un estudio de caso.

El supuesto de esta investigación destaca que las juventudes trabajadoras sostienen una lucha permanente para mejorar sus condiciones de trabajo y que en sus expresiones se configuran nuevas formas de resistencia. Concluimos que las juventudes trabajadoras despliegan diversas estrategias y acciones de resistencia reconfigurando la expresión del conflicto en el trabajo, sin embargo no consiguen mejorar sus condiciones de empleo.

En este artículo, primero se recuperan los debates sobre el proceso de trabajo, la transformación del trabajo en los servicios haciendo referencia al avance y persistencia del fenómeno de la precariedad y las nuevas resistencias. Luego se desarrollan los aspectos metodológicos de la investigación y se exponen los resultados señalando las características del mercado de trabajo en el Gran San Juan (Argentina), las complejidades en el comercio minorista tradicional para introducir a las formas de gestión y control del trabajo en dichos establecimientos. Posteriormente se caracterizan los conflictos y las resistencias en el trabajo y por último, las conclusiones.

\section{Debates sobre el proceso de trabajo}

El debate sobre la teoría del proceso de trabajo recupera la perspectiva marxista sobre el modo de producción capitalista. Entre los estudios en torno a los inicios de la revolución industrial se enfatiza la subordinación de los trabajadores a las máquinas y a la crisis de los oficios. Los aportes de Marx en El Capital (2009) destacan con solvencia ese punto al diferenciar entre valor de la fuerza de trabajo y trabajo e indicar que el valor de la fuerza de trabajo se corresponde con las mercancías (bienes y servicios) necesarios para la reposición/reproducción de los/as trabajadores/as junto a sus familias y no con el valor generado por el trabajador asalariado durante la jornada de trabajo. Es por ello, como señala De la Garza Toledo y Hernández (2019) que "(...) el capital para cumplir su función de explotación (extracción de plusvalía) tiene que dominar (controlar) al trabajador dentro del proceso de trabajo" (p. 2).

Sobre el eje del control, el debate sobre el proceso de trabajo, en términos generales, sostiene que el propietario de los medios de producción al requerir de forma constante “(...) la transformación y adaptación de la fuerza de trabajo como instrumento de valorización del capital” (p. 170) ajusta e innova sus estrategias para 
lograr un control efectivo del proceso de trabajo a la vez que los trabajadores y las trabajadoras, que solo disponen de su fuerza de trabajo para intercambiar por un salario, se resisten a la progresiva explotación y alienación en sus espacios de trabajo (Soria, 2018). En esa relación se articularán diferentes elementos de coerción, legitimación y consentimiento, donde el predominio de cada uno corresponderá a una construcción interactiva que combina “(...) la historicidad del proceso (disociación del productor libre de los medios de producción), el carácter fetichista (con la distinción del trabajo), la relación de subordinación y el componente subjetivo-vivo de la misma (la resistencia del trabajador a convertirse en salario, en mercancía)" (Silver, 2005 en Soria, 2018, p. 171), destacando además que esta relación de poder entre capital y trabajo es indeterminada, ya que el control no es total y el conflicto se constituye como una vía de transformación de esa relación.

Este debate se ha desplegado en diferentes etapas también en sintonía con las discusiones en torno a los paradigmas productivos señalados en cada época. La etapa fundacional (con eje en el paradigma taylorista-fordista), discute sobre los efectos de la división del trabajo, donde la intensificación en la descualificación de los empleos permitió el perfeccionamiento de las formas de control y explotación por parte de los propietarios (Braverman, 1974). En la segunda etapa, se hace énfasis en el papel de la acción y las experiencias subjetivas en el proceso de trabajo siendo uno de los aportes más importantes sobre la propuesta de "manufacturar consentimiento" (Burawoy, 1979) donde se explica el entramado en el que los mecanismos de control empresarial, más sutiles, buscan que los trabajadores y las trabajadoras contribuyan activamente a los fines de la empresa. En estos términos, Burawoy (1979) considera que la dominación del capital sobre el trabajo va de una hegemonía sostenida por la coerción a otra sobre la base del consenso o en todo caso la combinación de ellas.

Entre los estudios posteriores que corresponden a la tercera etapa, buscan explicar qué nuevas formas de control y gestión del trabajo se despliegan en sintonía con los procesos de flexibilización en el trabajo, el aumento de la precariedad y el trabajo informal. Desde los años noventa, parte de los estudios dentro del debate sobre la teoría del trabajo, redirigen la discusión sobre la situación del sector de servicios en el marco del patrón de acumulación flexible 2 . Soria (2018) destaca que "las exigencias actuales se basan, desde los discursos gerenciales, en la responsabilidad, la creatividad, la capacidad de involucramiento y el trabajo en el equipo, lo que traería como efectos bajos niveles de ausentismo, mayor aceptación de los cambios y mejores actitudes hacia la organización" (p. 173) Sin embargo, las estrategias que favorecen la iniciativa, la cualificación y la autonomía:

2. Según Soria (2018): “(...) el paradigma de la flexibilidad busca la readaptación de los trabajadores para nuevas tareas, capacitados para responder activa y autónomamente” (p. 173). 
“(...) se convierten en nuevos dispositivos de control que, en términos subjetivos, pretenden la interiorización de los valores empresariales procurando una gestión individual de los trabajadores, la inhibición de identidades laborales colectivas y los procesos de despolitización que asienten las relaciones conflictivas sobre nuevas bases, buscando que las resistencias se conviertan en aportaciones activas" (Soria, 2018, p. 173).

En esos términos, los estudios sobre la teoría del proceso de trabajo que se direccionan al estudio del comercio minorista rescatan como contextos esos procesos y es por ello que registran experiencias similares y se han enfocado en base a los cambios y transformaciones sobre la demanda de habilidades "blandas" (soft-skills) de los trabajadores y las trabajadoras. Bozkurt y Gurgulis (2011) plantean que a pesar de configurarse como un sector que emplea a trabajadores y trabajadoras usualmente con baja calificación, algunos sub-rubros como de venta de artículos de informática requieren de personas con mayor calificación, tal como indican Mason y Osborne (2008). Lo cierto es que existen cambios en las habilidades exigidas por las grandes cadenas de negocios minoristas, es decir, mayor demanda en lo que denominan como trabajo estético y emocional (imagen personal "adecuada" y habilidades de venta), a fin de adaptarse de mejor forma a las demandas de los y las clientes (Nickson, Price, Baxter-Reid y Hurrel, 2016; Pettinguer, 2005; Williams y Connell, 2010).

Otros estudios como los de Brook (2009) e Ikeler (2015) destacan la descualificación creciente de la actividad en relación a los conocimientos demandados y las interacciones prescriptas, siendo lo emocional una actuación superficial. Sin embargo, señalan en conjunto la heterogeneidad del sector, las diferencias respecto a la especialización en la venta de productos, las diferencias en complejidad en términos relacionales con los clientes junto con las condiciones de empleo como factores influyentes. Otras investigaciones como las de Nickson et al. (2016) destacan en estos espacios la combinación de elementos de control y gestión del trabajo tradicional y del paradigma flexible, es decir, vigilancia, control burocrático, control tecnológico junto con evaluaciones individuales e identificación con valores de la empresa y autoregulación.

\section{La transformación del trabajo en los servicios y el trabajo precario}

Las transformaciones en los procesos productivos han dado lugar a la crisis de los modelos-paradigmas clásicos de producción: taylorismo-fordismo frente al modelo japonés o toyotismo. El avance paulatino del sector de servicios sobre el industrial al contribuir más al producto y al empleo en la mayoría de las economías junto con la emergencia de nuevas figuras de empleo trabajo clásico, no clásico (De la Garza Tole- 
do, 2011), trabajo típico, atípico, formal e informal (Favieri, 2018) implicaron la crisis del referente empírico tradicional ${ }^{3}$.

Para De la Garza Toledo y Hernández (2019) teorizar sobre la configuración socio técnica y productiva en los servicios, hay que tener en cuenta que se trata de un sector heterogéneo y por ello es necesario situarlo en relación al contexto tecnológico, a la organización, a las relaciones laborales, a la cultura, al perfil de la mano de obra y los modos de relación cara a cara o mediada entre las personas incluyendo contextos externos (situación del mercado de trabajo, estructuras macroeconómicas, culturas laborales y gerenciales, entre otras) y lo específico que refiere a las características particulares (nacional, local o las propias del establecimiento). Por lo que agrega que no es necesario subsumir estas expresiones en modelos "universalistas", de esta forma dirá que es más preciso referirse a configuración antes que a modelo. El término de configuración admite: a) contradicciones y discontinuidades entre los elementos que conforman a un sector; b) que las transformaciones en la configuración de un sector, en un establecimiento, corresponde a los sujetos, de esta forma las acciones pueden llegar a cooperación o conflicto y c) las relaciones (y comportamientos) en términos de configuración no son resultado único de las presiones estructurales-configuracionales (De la Garza Toledo y Hernández, 2019).

Se destaca que en la configuración del empleo en el sector de servicios existen tres dimensiones, que también podrían sostenerse para toda relación de trabajo, estas son: la dimensión emocional, la estética y la cognitiva. La dimensión emocional refiere a una situación común “(...) de todo trabajo como relación social y con los medios de producción” (Scheler, 2003 en De la Garza Toledo y Hernández, 2019, p. 13). Se enfatiza una construcción emocional entre empleado y cliente (Hansen, 2012 en De la Garza Toledo y Hernández, 2019, p.13) y los resultados de la combinación de las relaciones según las formas en que se emplean la tecnología, la organización del trabajo y el perfil de la mano de obra, entre otras. En cuanto a la dimensión estética, se pone el acento en el “(...) lenguaje del cuerpo" (Hienich, 2001 en De la Garza, 2019, p. 13) donde la interacción definirá el significado que adquieren los cuerpos (Wolkkowitz, 2006 en De la Garza Toledo y Hernández, 2019) y por último, la dimensión cognitiva como aquella donde se generan conocimientos con significados útiles (para posteriores trabajos) y se aprovechan los conocimientos tácitos en el trabajo" (De la Garza Toledo y Hernández, 2019).

En sintonía, estas nuevas configuraciones asociadas al sector de servicios se combinan con nuevas figuras del empleo. La flexibilización de las relaciones laborales

3. La figura de obrero asalariado industrial especializado de trabajo estable, registrado, con tareas repetitivas, con trabajo fuera de casa a un sujeto del sector de servicios polivalente (De la Garza Toledo y Hernández, 2019; Soria, 2018). 
(Mora-Salas y de Oliveira 2009; Neffa, Battistuzzi y Suárez Maestre, 2008), permitieron la emergencia de empleos a tiempo parcial, de carácter temporal, a través de agencias, con posibilidad de tercerizar (subcontratar) a personas trabajadoras (Maurizio, 2016) incrementando la inestabilidad, la incertidumbre e inseguridad en el empleo. Estas nuevas formas, se caracterizan también por agregar más actividades en periodos cortos de tiempo, incrementar funciones por puesto de trabajo (polifuncionalidad), bajos salarios y horarios flexibles, medidas que en conjunto, lograron abaratar el costo de la mano de obra y la transferencia de responsabilidades y riesgos a quienes trabajan (OIT-ACTRAV, 2012).

Estas situaciones pueden desplegarse de forma conjunta o separada y dependiendo de ello, será un empleo más intensamente precario que otro con menos atributos. A la vez, pueden agregarse otras características, más vinculadas con la actividad trabajo y tienen que ver con aspectos tales como inseguridad (incertidumbre, inestabilidad), cansancio, aceleración y percepción negativa sobre el trabajo. De esta manera se destaca que la precariedad es un fenómeno multidimensional (gran cantidad de variables e indicadores intervinientes) y cuya expresión difiere en cada caso (intensidad y agregación).

Estas características sobre el empleo, se intensificaron durante los años noventa en Argentina, a partir del despliegue de políticas de re-estructuración productiva impulsadas por la flexibilización de la legislación laboral acorde a los lineamientos del "Consenso de Washington" (Basualdo y Bona, 2017), permitiendo la aparición, cada vez más usual, de empleos precarios. Durante el siguiente periodo (2003-2015), a pesar de reducir su presencia en el mercado de trabajo, en parte por la reactivación económica, el crecimiento del empleo privado registrado y las políticas dirigidas al sector del trabajo, el fenómeno de la precariedad persistió y se consolida en los últimos años, impactando de forma diferencial en diversas regiones, sectores de actividad y grupos de población, siendo las poblaciones jóvenes las más afectadas, ya que, además de encontrar dificultades para ingresar y establecerse en el mercado de trabajo en periodos de crisis y crecimiento económico, suelen vincularse mediante empleos precarios (Bertranou, Jiménez y Jiménez, 2017).

\section{Las nuevas resistencias}

Así como sucedió con la crisis de los referentes empíricos en los estudios tradicionales sobre el trabajo, ocurrió lo mismo en el debate sobre la teoría del proceso de trabajo para el registro de las expresiones de conflicto y resistencia, siendo en la actualidad un debate abierto (Soria, 2018). Las expresiones tradicionales asociadas a estrategias y acciones de tipo colectivo, organizadas con frecuencia por sindicatos, visibilizadas en manifestaciones multitudinarias o grandes huelgas perdieron el impacto que gozaron durante gran parte del siglo XX. 
La discusión en torno a las "nuevas resistencias" frente a las reconocidas como "tradicionales" recuperan los descriptores, en términos comparativos, sobre: a) intensidad y tamaño (Hyman, 1981), b) expresiones de los modos de politización y la direccionalidad política (Beaud y Pialoux, 2009; Silver, 2005 en Soria, 2018) y c) las formas de despliegue (Silver, 2005 en Soria, 2018).

Las resistencias de carácter colectivo son de gran intensidad cuyas formas de despliegue público (huelgas, manifestaciones, entre otras) implican mayor organización (son dirigidas generalmente por sindicatos) al tiempo que involucran (e interpelan) al colectivo de trabajadores y trabajadoras no solo en los términos que dan origen a un conflicto particular sino también por la direccionalidad política que reflejan. Beaud y Pialoux (2009) al igual que Silver (2005) señalan este aspecto como una expresión claramente identificable en el derrotero de la lucha de clases y supone, por lo tanto, un modo de politización fuerte, sin embargo, las "nuevas resistencias" suelen identificarse como su expresión negativa. Son, con frecuencia, iniciativas de tipo individual (atomizadas) cuyo despliegue es más bien solapado, oculto, espontáneo e invisibilizado (Beaud y Pialoux, 2009).

Desde el debate actual de la teoría del proceso de trabajo pueden agruparse en dos grandes expresiones, como a) las situaciones de simulación: que disfrazan el sentido de disciplina (reglas y normas) como el falso discurso (Collinson, 2003), el "flanelling" (afirmación equivoca, práctica como actuación, disposición irónica, escepticismo y cinismo) (Fleming y Sewell, 2002; Fleming, 2005) y el revés discursivo (Lutgen-Sandvik, 2006) y b) las de fuga: como expresiones de ausentismo, resignación (Collinson, 2003); elución del deber (Fleming y Sewell, 2002); trabajar lento, ser menos cooperativo (Ezzamel y Willmott, 2008), desobediencia y éxodo (Lutgen-Sandvik, 2006).

En cuanto a su efectividad y por sus características de su baja intensidad se discute si de hecho son expresiones transformadoras o que si modifican el entorno de trabajo, Scott (2000) plantea que estas acciones cotidianas logran conquistar mayor autonomía (aunque reducida), que el mencionado solapamiento e invisibilidad permite incrementar el margen de movimiento para actuar de forma discreta fuera del alcance de los mecanismos de control y gestión; sin embargo el éxito en este tipo de iniciativas es circunstancial, de todas formas, estas resistencias son "prácticas que ponen de manifiesto la ofensiva del capital sobre el trabajo y los inicios de formas (re) creadas y cotidianas que desafían a la misma" (Soria, 2018, p. 188) y que demuestran la presencia constante de conflictividad en los espacios de trabajo.

En este artículo se retoman los aportes de Hyman (1981) cuando define a las resistencias "tradicionales" por su tamaño e intensidad, junto a los aportes de Silver (2005) y Beaud y Pialoux (2009) en relación a la direccionalidad política y las formas de despliegue. Esto será de utilidad para re-pensar la acción gremial en entornos precarios de trabajo. Por otro lado, las contribuciones de Scott (2000), Collinson (2003), 
Fleming y Sewell (2005), Fleming (2005), Lutgen-Sandvik (2006), Ezzamel y Willmott (2008) y Soria (2018) permiten definir variables e indicadores de registro en torno a las nuevas resistencias (simulación y fuga), que serán reconstruidas durante el análisis de los casos.

En términos generales, aquí se sostiene que las resistencias tradicionales constituyen una expresión aún vigente incluso en entornos precarios de trabajo, cuyas expresiones son cercanas a las estrategias y acciones de carácter sindical donde la capacidad de movilización (número), expresión pública del reclamo (gran visibilización) y métodos empleados (paro, denuncias ante los organismos reguladores del Estado) terminan por definirlas. Por otra parte, se retoman a las nuevas resistencias como una expresión frecuente de carácter individual, invisibles a nivel público y cuyas expresiones pueden observarse de forma habitual en diferentes situaciones de precariedad laboral como ocurre con los casos bajo estudio. Es importante destacar que estas expresiones de resistencia pueden ocurrir al mismo tiempo o en diferentes momentos a lo largo de la relación laboral de una persona y por ello las dos contribuyen a enriquecer el debate en contexto.

\section{Las juventudes en el debate}

Las juventudes encuentran dificultades para ingresar y permanecer en el mercado de trabajo constituyéndose un problema de larga data. Entre algunos de los principales motivos que explican la dificultad en el ingreso ubica a los trabajadores y las trabajadoras que acceden por primera vez a un empleo, la baja calificación y nivel educativo, falta de experiencia de trabajo y/o desarticulación de expectativas de empresas frente a las ofertas juveniles que atienden a las demandas específicas según el sector de actividad que se trate (Groisman y Scofienza, 2014; Jacinto y Chitarroni, 2010; Weller, 2003, 2006), situaciones que se complejizan aún más sobre el grupo juvenil en periodos de crisis y crecimiento económico como fue mencionado (Bertranou et al., 2017).

Por otra parte, cuando logran acceder a un empleo, lo hacen con cierta frecuencia desde contratos temporales, por tiempo determinado (alta rotación), o se constituyen en desempleo intermitente, con bajos salarios y sin estar debidamente registrados ante la autoridad laboral (sin derechos laborales). La precariedad resultante combina entonces situaciones de inestabilidad, inseguridad e incertidumbre en el puesto de trabajo configurándose como una situación de alcance local y regional (OIT, 2019).

De esta forma, las juventudes se posicionan como uno de los grupos (junto a las mujeres y la población migrante) donde converge con mayor intensidad el fenómeno de la precariedad laboral (OIT, 2013b) y este aspecto es el eje que define el criterio de elección como exponentes principales para estudiarlas en sus conflictos y resistencias. 
La precariedad como fenómeno tiene efectos transformadores sobre los modos de la acción colectiva y la solidaridad entre los trabajadores y las trabajadoras. Castell (2000) y Wyczykier (2012) señalan la presencia de dos procesos simultáneos, uno de descolectivización y otro de individualización, poniendo en crisis a las organizaciones sindicales tradicionales y promoviendo la aparición de estrategias de lucha donde se asumen los riesgos de forma individual, incluso por no reconocerse como sujetos de derecho (Santamaría López, 2018). Por otro lado, las transformaciones en el mundo del trabajo también se refleja con la crisis de las expresiones clásicas de conflictividad organizadas sindicalmente frente a la emergencia o bien registro de nuevas estrategias y acciones de resistencia (comentadas en el debate precedente) cuyos aspectos conceptuales se retoman para el análisis de la situación juvenil.

\section{Metodología}

Esta investigación se enmarca desde una metodología cualitativa a partir de estudio de caso simple, instrumental (Stake, 1995) o crítico (Yin, 1994). Se realizaron 19 entrevistas semi-estructuradas a jóvenes trabajadores y trabajadoras y 3 entrevistas a informantes clave ( 2 dirigentes sindicales y 1 a un referente empresarial).

La selección de los casos fue prevista conforme a los objetivos de investigación y se trató de jóvenes (hombres y mujeres) entre 16 a 30 años que trabajaban en comercios tradicionales de venta al por menor de artículos para el hogar, electrónica, alimentos y bebidas, ropa, calzado y marroquinería situados en el Gran San Juan (Departamentos Capital, Santa Lucía, Rawson, Rivadavia y Chimbas), Argentina en establecimientos comerciales de hasta 23 personas. Dentro del espacio-territorio elegido, se buscaron personas jóvenes dispuestas a ser entrevistadas y los nuevos casos, fueron hallados mediante la "técnica de bola de nieve" (por contacto, sugerencia y recomendación de los primeros entrevistados).

Por otro lado, se asume a la juventud como categoría sociológica. No se pretende homogeneizar ni reducir "la juventud" en una generalidad estadística sino que se hará énfasis en su constitución socio-histórica, relacional y situada. Dicha heterogeneidad al interior admite la existencia de varias configuraciones de "juventud(es)" sobre el mismo espacio en similares contextos y situaciones donde pueden existir elementos comunes/similares que los/as permita reconocerse como tales. En este sentido, los/as jóvenes son ante todo, jóvenes trabajadores/as, aspecto que los/as distingue del resto. Pero a la vez los/as jóvenes a entrevistar en sus "trabajos actuales" son una síntesis compleja, dinámica, relacional y contradictoria producto de sus trayectorias laborales, educativas y familiares.

Las entrevistas a jóvenes fueron realizadas durante el 3er trimestre de 2017 en los lugares de trabajo y fuera de los mismos, donde la observación no participante (en los establecimientos) permitió reconstruir detalles a partir los relatos obtenidos 
sobre el conjunto de entrevistas. La estrategia de análisis de los resultados desplegó los procedimientos del análisis de contenido cualitativo (Ruiz Olabuénaga, 2003) a fin de recuperar elementos que permitan reconstruir las relaciones que establecen los y las jóvenes trabajadores y trabajadoras con su trabajo en relación a las resistencias y conflictos, permitiendo su lectura, ordenamiento, reorganización y vinculación teórica con los sentidos y prácticas manifiestos en sus relatos en el ámbito de trabajo (De la Garza Toledo, 2018; Huberman y Miles, 1994 en Stecher, Godoy y Toro, 2010).

\section{Resultados}

\section{El mercado de trabajo en el Gran San Juan, Argentina}

Durante 2003-2017 se observa una mejora general sobre los principales indicadores del mercado de trabajo en el aglomerado Gran San Juan, sin embargo, las personas jóvenes continuaron como el grupo más propenso al trabajo precario y al desempleo. Su tasa de desocupación casi duplica las registradas para el total de población económicamente activa, mientras que 7 de cada 10 jóvenes trabajan en empleos no registrados.

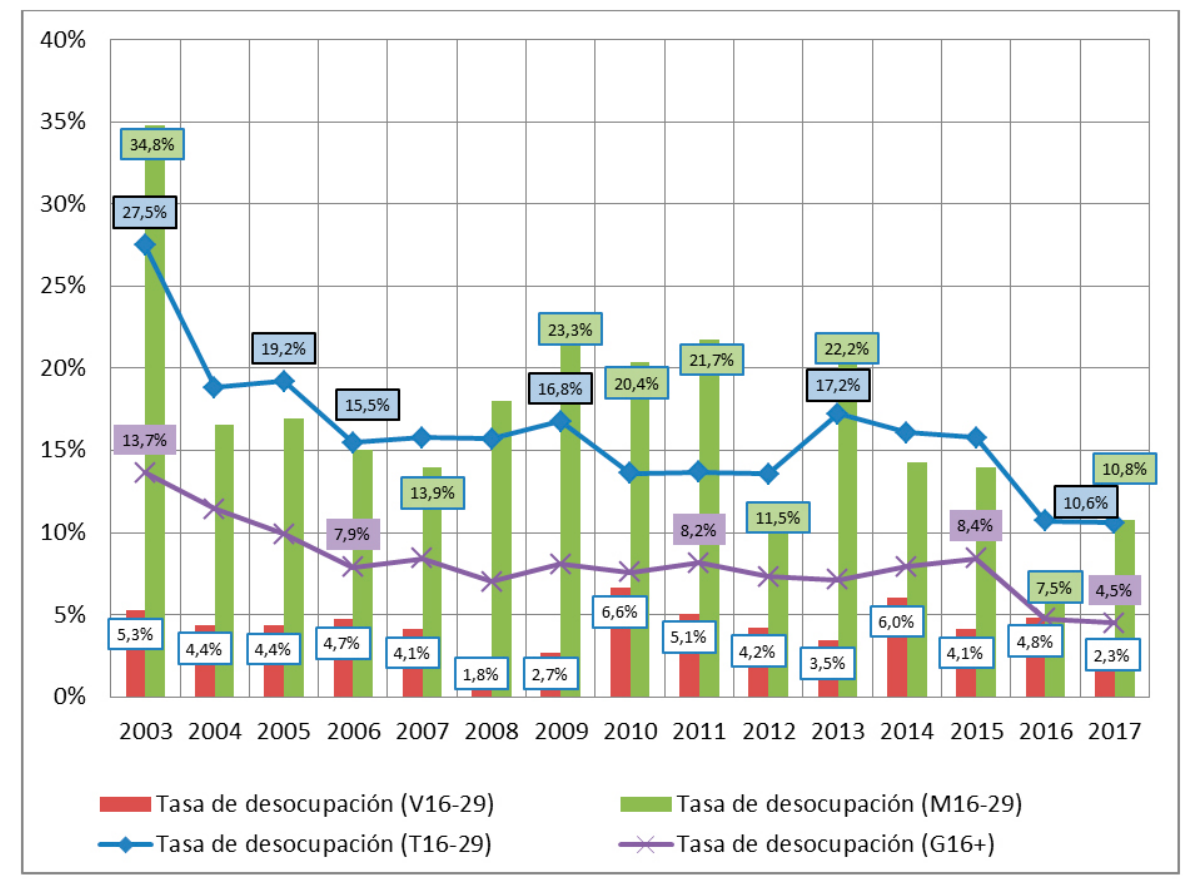

Figura1. Evolución de la tasa de desocupación juvenil por sexo. Aglomerado Gran San Juan. 3eros Trimestres. Años 2003-2017. Valores relativos.

Fuente: Elaboración propia en base a datos de la Encuesta Permanente de Hogares (EPHINDEC) Nota: "V" corresponde a Varón y "M" corresponde a mujer. 


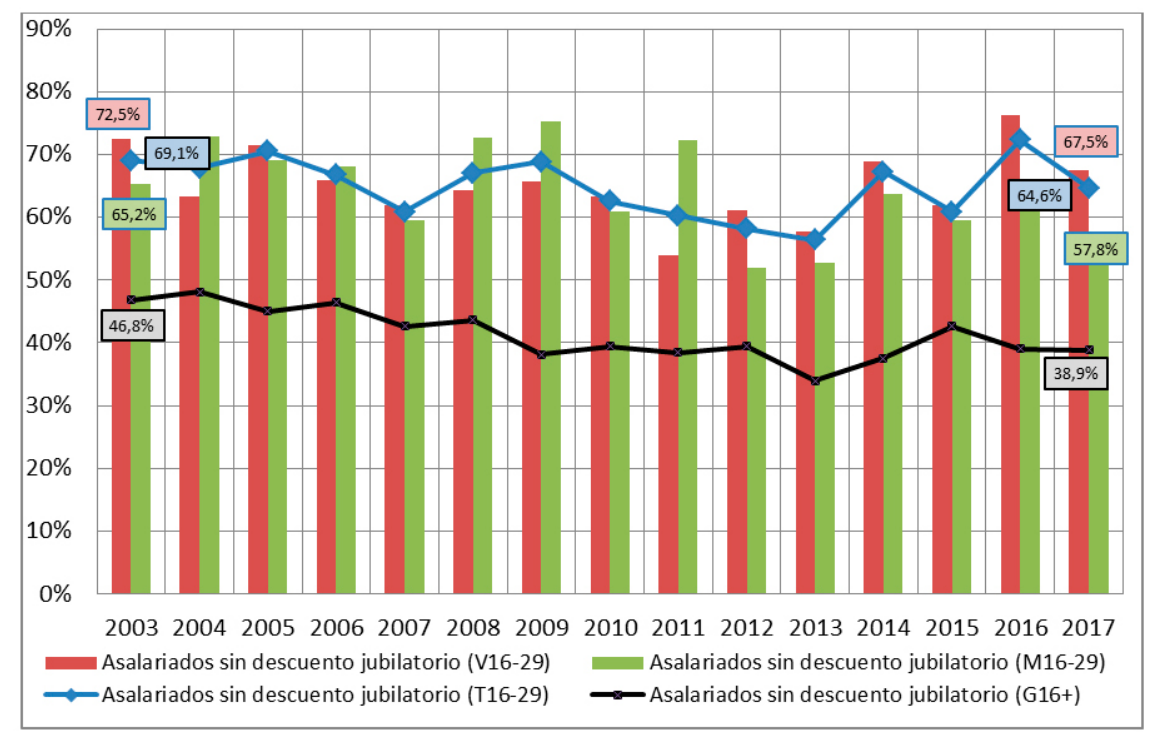

Figura 2. Ocupados asalariados sin descuento jubilatorio. Gran San Juan. 3eros trimestres. Años 2003-2017. Valores relativos.

Fuente: Elaboración propia en base a datos de la Encuesta Permanente de Hogares (EPHINDEC). Nota: "V" corresponde a Varón y "M" corresponde a mujer.

Respecto de la inserción laboral, la mayoría de las personas jóvenes ingresan al mercado de trabajo como asalariados, sin embargo, un $61 \%$ de ellos, en el tercer trimestre de 2016, no se encuentran registrados. En comparación con los valores observados para el resto de la población, la proporción de asalariados no registrados es del 39\% para el mismo trimestre del año; esto señala que las personas jóvenes se encuentran más expuestas a conseguir trabajos precarios que el resto de la población económicamente activa, influyendo también en términos comparativos de estabilidad y permanencia.

En relación a los sectores, la población joven consigue trabajos mayoritariamente en "industria manufacturera" (20\%), "comercio" (19\%) y "construcción" (17\%). Por otro lado, el $59 \%$ de las personas jóvenes ocupadas trabaja en empresas de hasta 5 personas y un $37,1 \%$ en medianas empresas ( 6 a 40 personas), sólo un 3,8\% lo hace en grandes empresas. En cuanto a la calificación ocupacional, la juventud se caracteriza por desempeñarse mayoritariamente en ocupaciones operativas (45,6\% en 2016), en segundo lugar, se encuentran en el desempeño de trabajos no calificados (39,9\% en 2016). Respecto de 2003, se observa una disminución de participación juvenil en ocupaciones de carácter operativo (de 56,9\% en 2003 a 45,6\% en 2016) y un aumento en los no calificados (de 30,8\% en 2003 a 39,9\% en 2016), al igual que en profesionales (3,5\% en 2003 a 4,7\% en 2016). 
Tabla1. Características de inserción laboral. Gran San Juan. 3eros trimestres. Años 2003 y 2016 . Valores relativos.

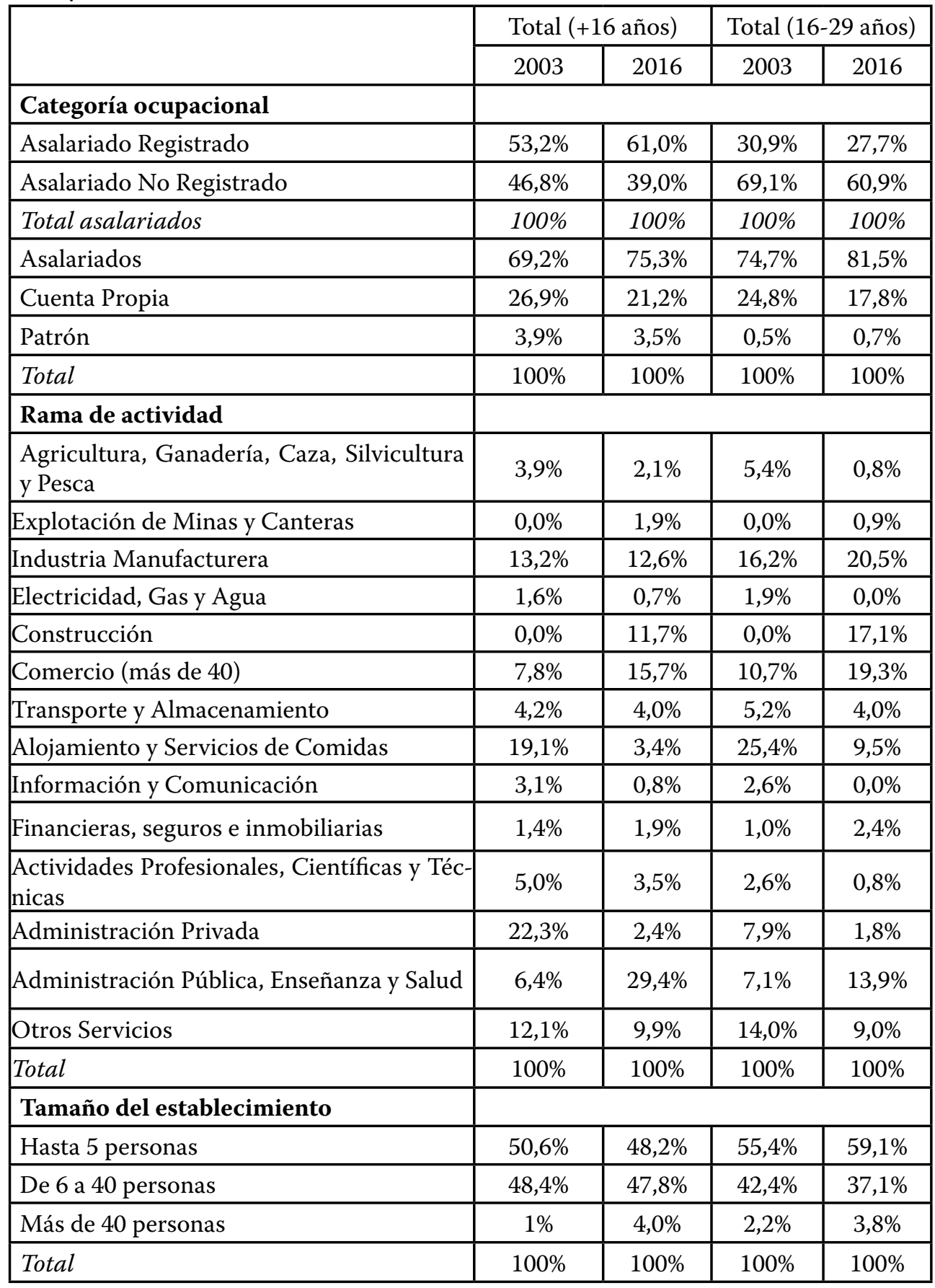




\begin{tabular}{|l|c|c|c|c|}
\hline Calificación ocupacional & \multicolumn{4}{|l|}{} \\
\hline Profesional & $8,3 \%$ & $11,4 \%$ & $3,5 \%$ & $4,7 \%$ \\
\hline Técnica & $19,6 \%$ & $16,6 \%$ & $8,8 \%$ & $9,9 \%$ \\
\hline Operativa & $50,9 \%$ & $52,3 \%$ & $56,9 \%$ & $45,6 \%$ \\
\hline No calificado & $21,2 \%$ & $19,7 \%$ & $30,8 \%$ & $39,9 \%$ \\
\hline Total & $100 \%$ & $100 \%$ & $100 \%$ & $100 \%$ \\
\hline
\end{tabular}

Fuente: Elaboración propia en base a datos de la Encuesta Permanente de Hogares (EPH-

INDEC).

\section{Las complejidades del comercio minorista tradicional}

En la configuración del trabajo en el comercio minorista esta relación se complejiza en cuanto al tamaño de la empresa. Primero en su expresión a nivel local, ya que el comercio minorista tradicional y de pequeñas y medianas empresas sostienen rasgos "tradicionales" diferentes a los observados en la mayoría de los estudios sobre esta dimensión que se enfocan a los servicios encuadrados por empresas multinacionales o nacionales con establecimientos que al por menor terminan organizándose sobre configuraciones modernas donde destacan la presencia de establecimientos multirubro (Abal Medina, 2005; Fernández Milmanda, 2010; Guiamet, 2017; Radiciotti y D’Urso, 2013;) a rubros específicos (aquí se incluyen establecimientos de grandes superficies como supermercados y tiendas especializadas como aquellos de venta de artículos electrónicos, para el hogar solo por nombrar algunos); a ello se suman formas flexibles de gestión del trabajo (contratos a corto plazo o plazo fijo, eventuales, con jornadas de trabajo adaptables a las necesidades del establecimiento), incorporación de nuevas tecnologías de control (cámaras, software de registro electrónico de productos, de asistencia, publicidad digital, compras desde el hogar, entre otras) y profesionalización de la administración (contratación y organización integral de equipos con especialistas en áreas contables, de marketing, legales, sistemas, entre otras) (Lira, 2005 en Stecher, Godoy y Toro, 2010; OIT, 2014).

Estos formatos cumplen un rol crucial en la determinación de las relaciones de trabajo al interior del establecimiento entre empleadores, empleados y clientes; quizás de forma más homogénea con expresiones claramente identificables tanto en términos de control y gestión del proceso de trabajo. Las configuraciones locales "tradicionales" en los comercios minoristas estas acepciones no son claras, de hecho podría advertirse en base a estudios empíricos (Blousson, 2009; Kosiak de Gesualdo, Modesto, Etchevarría y Gesualdo, 2014) su persistencia pero en transformación, en procesos de cambio al interior de esos establecimientos que combinan en parte herramientas del comercio moderno junto con las clásicas de gestión del trabajo. 
En principio se destaca una concentración de los negocios minoristas por parte de grandes empresas de capitales de origen nacional y multinacional (internacionalización) que desde los años noventa en la región como en Argentina y al igual que en San Juan, han logrado sostener un avance continuo sobre los comercios tradicionales (OIT, 2014), al tiempo que explican la sobrevivencia de este tipo de configuraciones, en términos de proximidad y relación con el cliente; su "intensa relación" ajustada a la demanda, la diversidad y la adaptabilidad local (Kosiak de Gesualdo, Modesto, Etchevarría y Gesualdo, 2014) y su especialidad entronizada por la independencia y las relaciones personales con los clientes (Blousson, 2009).

En San Juan las microempresas vinculadas al comercio son mayoritarias en comparación con servicios e industria logrando el 73,3\% en ese tipo de establecimientos. Puede asumirse que existe una relación entre tamaño y origen-perfil del capital. Las firmas de capitales multinacionales y nacionales por su constitución en red y ampliación global no se despliegan como micro empresas. En general lo hacen en espacios comerciales más amplios demandando más trabajadores y trabajadoras lo que los posiciona hacia las grandes empresas siendo establecimientos pequeños y medianos los que abren al público en venta minorista ${ }^{4}$. Formatos como los asignados a los comercios tradicionales, de capitales locales, se ubican mayoritariamente como microempresas.

Es importante destacar que las situaciones observadas en el comercio minorista en general y en particular sobre los comercios tradicionales, reflejan las transformaciones en los procesos de trabajo iniciadas en los años setentas y con mayor intensidad en los años noventa y dos mil con la aparición de comercios minoristas dirigidos por empresas de capital multinacional.

Entre los establecimientos sobre los que se realizaron las entrevistas a jóvenes trabajadores y trabajadoras del comercio (ver Tabla 2 en anexo), se destacan 2 que no corresponden al modelo tradicional: sus capitales son de origen nacional, se despliegan en grandes superficies y disponen de varios locales asociados en diferentes puntos de la provincia y el país. Como organizaciones proceden con gerenciamiento profesional. Otros comercios cuyos capitales son de origen locales se despliegan en pequeñas y medianas superficies, a excepción de un comercio bajo el modelo de franquicia, el resto no tiene ningún tipo de vinculación con otros locales, no se despliegan como cadenas comerciales y la organización es de tipo familiar con participación operativa del dueño o parientes directos.

4. Según el Observatorio de Empleo y Dinámica Empresarial del Ministerio de Trabajo de la Nación Argentina, los topes máximos para definir tamaño de empresa según cantidad de empleados en el comercio minorista es de hasta 5 trabajadores y trabajadoras para las microempresas, 23 para las pequeñas y hasta 67 en las medianas, superado ese valor, corresponde a grandes empresas. También para su definición se incluyen montos estimativos de facturación pero aquí no se incluyen. 


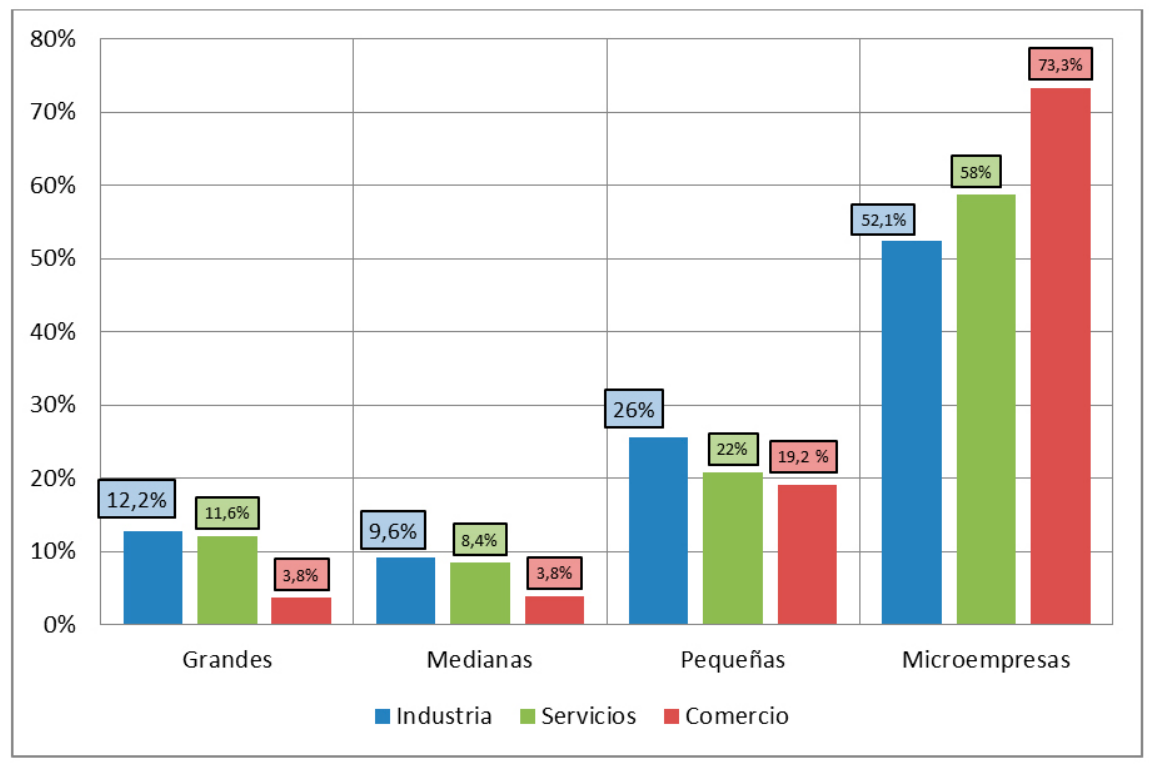

Figura 3. Empresas por sector y tamaño- al cierre del año 2016. San Juan. Valores relativos.

Fuente: Elaboración propia en base a datos del Observatorio de Empleo y Dinámica Empresarial - MTEySS en base a SIPA.

Nota: Las empresas se encuentran clasificadas según las provincias donde declaran sus ocupados.

\section{Formas de gestión y control del trabajo en el comercio minorista tradicional}

La definición de gestión y control de la fuerza de trabajo puede incluir aspectos que describen las decisiones sobre la selección de perfiles de trabajadores y trabajadoras, esquemas de remuneración, actividades y tareas, modelos jerárquicos, división de tareas, mecanismos de control (coerción y consensos) para el logro de objetivos empresariales (Vargas, 2019). A partir del relato de los casos entrevistados se caracterizan primero algunos elementos que lo definen en términos globales indicando organización administrativa y perfiles solicitados, situaciones de registro, retribuciones salariales, actividades y el control de desempeño. Todas estas dimensiones dan cuenta de algunos aspectos que determinan una configuración socio-técnica particular (De la Garza Toledo y Hernández, 2019) que ayudará a caracterizar el trabajo en el comercio minorista tradicional en Gran San Juan al tiempo que permite contextualizar el análisis de las situaciones de conflicto en los establecimientos. 
a) Organización administrativa y perfiles solicitados

En los comercios minoristas tradicionales, las propuestas se caracterizan por ser empresas usualmente de carácter familiar y “(..) disponen de escaso a nulo nivel de profesionalización en gerenciamiento" (Blousson, 2009), es decir, la dirección del negocio es de forma intuitiva, se proponen como intermediarios entre fabricante o prestador de servicios y clientes, se sostiene una participación total del propietario en todos los ámbitos, sin evidenciarse propuestas (estrategia y planificación) de diseño profesional y despliegue conforme a las situaciones de coyuntura (Blousson, 2009).

Si bien varias de las características que menciona Blousson (2009) se observan en los establecimientos de referencia a partir del relato de los casos entrevistados, este autor destaca que en los comercios tradicionales no existe una estructura de jerarquización interna que permita identificar la presencia de mandos medios, sin embargo se destaca una estructuración informal de jerarquización que se asigna eventualmente a los trabajadores y/o las trabajadoras con mayor antigüedad y que logran mayor confianza con los empleadores.

Los relatos de entrevista destacan la importante valoración por parte de los empleadores sobre la disponibilidad horaria y responsabilidad en su cumplimiento. En términos de flexibilidad, resulta estratégico para atender las urgencias que pueden acontecer en los establecimientos frente a una eventual ausencia o crecimiento en el flujo de clientes. Por otro lado, en relación a la responsabilidad, las referencias (y la confianza sobre las fuentes que puedan tener los empleadores) suelen ser el camino de entrada para conseguir una entrevista de trabajo y lograr el ingreso.

En relación a la certificación mínima, en tanto máximo nivel educativo alcanzado, como poseer título final de escuela secundaria completa puede ser un factor de elección al igual que la certificación de manejo básico de software computacional (procesador de textos, gestión de base de datos, entre otras) y herramientas de trabajo (cajas registradoras, instrumentos de cobro - posnet- o troqueladoras, por ejemplo) sin embargo, esto se ubica en segundo plano ya que para la realización de la actividad se valoran con mayor estima los primeros criterios.

Esto se encuentra en sintonía en términos de tecnología. Para los comercios tradicionales existe una "transformación paulatina" o en "transición" en la integración de algunos aspectos logísticos como "cajas registradoras automatizadas, lectores ópticos, escáner, sistemas de informatización sobre inventarios" (OIT, 2014); "sistemas de cámaras" (Kosiak de Gesualdo et al., 2014); “consultores específicos” en el reclutamiento eventual de contables, profesionales del marketing, aunque con efectos residuales (Blousson, 2009) siendo también señalados para los establecimientos referenciados por los y las jóvenes en entrevistas. 
b) Las situaciones de registro

El registro identifica los términos de regulación del empleo con respecto a su configuración legal en relación al acuerdo celebrado entre las partes. Las variantes observadas ubicaron a los casos entrevistados en 3 figuras: registrados (4 casos), parcialmente registrados (8 casos) y no registrados (7 casos). Sobre cada figura se observan situaciones de precariedad en diferentes intensidades.

Los casos que transcurren en una situación de registro pleno (empleados declarados ante la autoridad laboral competente) poseen más beneficios que el resto de las figuras mencionadas, gozan de salarios conformes a arreglos paritarios, protección social, aportes jubilatorios, vacaciones, entre otras, expresando el umbral de precariedad más bajo, sin embargo, señalan situaciones de incumplimiento permanentes sobre alguno de los derechos que, en términos formales, deberían respetarse, por ejemplo: cesión de días extra de franco, extensión de la jornada en días especiales sin retribuir pago de horas extra o la obligación de realizar actividades no previamente convenidas en el contrato.

El grupo de casos "parcialmente registrado", expresan situaciones donde el registro administrativo de una jornada simple de trabajo (4 horas), es efectivamente denunciada a las autoridades de regulación del trabajo, pero en los hechos, son jóvenes que trabajan por jornada completa (8hs y más), es decir, la mitad de la jornada no está registrada. Sobre esta modalidad, los casos entrevistados aseguran que no sólo es una estrategia de los empleadores para ahorrar en gastos, sino también, una estrategia para evitar sanciones en los recorridos diurnos de las inspecciones de los organismos de control (Subsecretaría de Trabajo, Superintendencia de Trabajo de la Nación).

"Entonces la mayoría de los locales tienen empleados en negro en la tarde y no en la mañana. Y en la mañana tienen solamente uno, dos. A la tarde están todos un desastre, se cierra a cualquier hora y todo eso" (Magdalena) ${ }^{5}$.

Por último, en los casos "no registrados", la celebración del contrato es "de palabra”, y lo convenido es probable que se modifique al poco tiempo. Lo que respecta al salario, a la extensión horaria y a las tareas y actividades, queda a disposición de las decisiones arbitrarias de quienes ofician como empleadores. Este es el grupo más vulnerable e inestable. En este régimen se incluyen también, las figuras de reemplazo temporarios (franqueros).

5. Los relatos de entrevista de jóvenes se colocarán en cursiva. Los nombres con los cuales se mencionan a los casos entrevistados fueron modificados para preservar el anonimato. 
c) Las retribuciones salariales

Continuando con lo anterior, la situación de registro se complementa con el régimen de retribuciones. El salario, se constituye como una de las razones más importantes para concretar el vínculo laboral, ya que responde directamente a las expectativas en torno a la satisfacción de las necesidades de los trabajadores y las trabajadoras y no sólo es obrador de sentido al inicio del vínculo, sino que además influye en la elección del régimen de jornada.

Para los trabajos no registrados o parcialmente registrados, el salario por jornada simple, según los casos entrevistados, se encontraban entre los 5000 a 6000 pesos argentinos y los de jornada completa hasta los 15000 pesos argentinos, sin embargo, por la situación de contrato, los montos finales eran variables y no se ajustaban tampoco a los aumentos paritarios consignados ${ }^{6}$. Esta diferenciación deja ver también el perfil de los entrevistados y las entrevistadas en sus obligaciones, necesidades y proyectos de vida.

Con el salario de media jornada, no pueden mantenerse de forma autónoma y habitualmente el dinero conseguido es destinado a actividades recreativas (salidas, gimnasio), de estudio (pago de cuotas en instituciones privadas), vestimenta o pago de servicios como el de telefonía celular. Mientras que en los casos de jornada completa, el salario se dirige al sostenimiento o colaboración con el grupo familiar propio (hijos y/o pareja) o, el de origen (padres y parientes en general), en todo caso, los casos entrevistados destacan que el salario es insuficiente o bien, limitado. Mabel y Amanda señalan:

"No se cumple con días de vacaciones, con el salario o sea lo que es el salario anual complementario, con el aguinaldo acá si lo pagan independientemente de que estás en negro, sí te lo pagan, pero hay muchos lugares que no lo pagan, la hora de trabajo nunca es lo que esta convenida o establecida" (Mabel).

“(...) yo no llego ni a los siete, ¿entendés? (...) no me alcanza, yo porque vivo en mi casa, salvo que compartas con alguien, no sé, un alquiler, pero si no, no se puede (...) está muy complicado" (Amanda).

d) Las actividades

La situación de registro y las retribuciones salariales terminan por explicarse junto con las actividades y tareas a desarrollar en el empleo. El trabajo en el comercio no solo consiste en "atender al público". Los relatos manifiestan otro gran conjunto

6. La Canasta Básica de Alimentos según INDEC para el 3er trimestre de 2017 era entre 13000 a 14000 pesos argentinos, mientras que el salario conforme arreglo paritario para vendedores con la menor antigüedad iba de los 18000 a 20000 pesos argentinos. 
de actividades que se ejecutan en el establecimiento, como por ejemplo: limpiar (pisos, ventanas, rejas, productos, baños, entre otras), ordenar productos, inventariar (colocar precios y códigos), confeccionar presupuestos para pedidos especiales, tareas orientadas a la confección de vidrieras y en algunos casos se agregan actividades como atención de caja (cuando la situación lo requiera) y vigilancia de clientes para evitar posibles robos.

Las tareas más usuales, de limpieza y orden en general, se realizan diariamente antes (pre-apertura) y después (pos-cierre) del establecimiento y las de stock, con la llegada de nueva mercadería; estas actividades se constituyen como prácticas habituales y los casos entrevistados las asumen desde el inicio de su vínculo laboral, sin embargo, no dejan de manifestar en sus relatos que esas actividades son "extraordinarias" y que deberían retribuirse:

"Todos hacemos todo, atendemos, menos la caja, todo, atendemos, recibimos, marcamos, ordenamos, seleccionamos, troquelamos, limpiamos la vidriera. Me pagan por la venta y les decía, 'a mí me pagan por vender no por limpiar. También ordenamos el depósito” (Melisa).

Otra dimensión cotidiana y característica del empleo en el sector, corresponde al flujo de personas que se suma a la ya habitual extensión horaria de la jornada y a la multiplicidad de tareas y actividades. El flujo de clientes, depende fundamentalmente del día que se trate. De lunes a jueves, es "relativamente tranquilo", lo casos entrevistados los describen como días desiertos, donde es usual el "tiempo muerto":

“(...) el tema son las horas de estar al pedo, no está bueno esto, no te sirve de experiencia, porque estoy al pedo, estoy esperando a que se pase el tiempo para irme, ¿entendés? (...) Estás esperando y decís 'Que pase el tiempo” (Amanda).

Pero entre viernes a domingo (incluyendo especialmente los días feriados) señalan un aumento importante de clientes, donde manifiestan sus exigencias e incluso la de los propietarios para atender con rapidez y encargarse además de cualquier eventualidad:

“(...) el trabajo con la gente es muy desgastante. O sea, sí, hay que aguantar muchas cosas a veces. Muy poca gente tiene el aguante (...) como que no te espera (...) insultan, son muy agresivos (...) Incluso al principio era como que uno se la aguantaba y bueno, no lo escuchabas (...) creen que una es como, viste, qué se yo... que tenés todo memorizado, y todos caen y dicen: 'Pero cómo no vas a saber lo que yo llevo siempre” (Pamela).

Estas situaciones se intensifican ampliamente en los días especiales (día del padre, de la madre, del niño, fin de año y reyes magos); días en el que habitualmente se em- 
plean más personas para atender a un flujo extraordinario de clientes. Se destaca en esta parte, que en general, los clientes para los casos entrevistados no son conflictivos, aunque alguna vez vivieron situaciones de tensión que implicaron gritos, insultos y recriminaciones por parte de ellos.

Agregado a la multiplicidad de tareas y actividades, a la extensión de las jornadas, se destacan los pocos días de descanso que logran conseguir en el mes. Exceptuando los casos registrados que tienen un día de descanso semanal y otro extra (variable y ajustado a las necesidades del establecimiento), el resto sólo tiene un día libre por semana, aspecto que termina por definir el sentido del trabajo en el comercio.

"Es la típica frase que dicen todos, sos esclava del comercio. Cuando vos trabajas en el comercio, o sea, con el horario que corresponde, acá que es cortado, sos esclavo, porque no tenés mañana y no tenés tarde, no tenés para vos tus horarios" (Martina).

Se expresa entonces una afirmación concreta de insuficiencia (en tanto día libre), que fortalece la noción del trabajo en el comercio relacionado a la cárcel, a la máquina, a "la esclavitud". También operan como momentos de renovación, de recuperación, no sólo en el sentido de cuerpo-máquina (que debe reponer energías para la jornada) sino como cuerpo-emoción, que reajusta la sensibilidad, el sentido fuera del mundo del trabajo. Por otro lado, los casos entrevistados dejan entrever las exigencias cognitivas y emocionales para el despliegue de sus actividades y tareas. En el primer caso, los conocimientos tácitos para la realización del trabajo en la realización de múltiples tareas y en el segundo el desgaste asociado a la postura emocional requerida para responder con efectividad y precisión a las peticiones del cliente y "aguantar" el maltrato si es el caso.

De esta forma, el trabajo en el comercio es caracterizado por los entrevistados y las entrevistadas como una actividad donde es usual la extensión de la jornada laboral, con salarios bajos o insuficientes, de intensidad variable dependiendo los días de la semana, con exigencias que demandan una interacción plena por parte de los trabajadores a fin de mejorar el servicio, con requerimientos de disponibilidad horaria y flexibilidad en la realización de tareas, pocos días de descanso y sin vistas de crecimiento o proyección ante un entorno de inseguridad e inestabilidad que combina diferentes intensidades de precariedad.

De esta forma, el trabajo en el comercio es caracterizado por los entrevistados y las entrevistadas como una actividad donde es usual la extensión de la jornada laboral, con salarios bajos o insuficientes, de intensidad variable dependiendo los días de la semana, con exigencias que demandan una interacción plena por parte de los trabajadores a fin de mejorar el servicio, con requerimientos de disponibilidad horaria y flexibilidad en la realización de tareas, pocos días de descanso y sin vistas de crecimiento o proyección ante un entorno de inseguridad e inestabilidad que combina diferentes intensidades de precariedad. 
e) El control del desempeño

Como se observó en el punto anterior, la distribución de tareas y actividades se ajustan a las eventualidades que presenta el contexto de venta en cada establecimiento y son agregativas conforme a la antigüedad de las personas que responden con efectividad en la realización de sus tareas y actividades. El control del tiempo sobre el desempeño de las actividades y la disposición en tanto "atención al público" y "disponibilidad" frente a la eventualidad, son aspectos centrales.

Los procedimientos de control implican: a) el establecimiento de ritmos (no demorarse con clientes para poder atender a otros), b) la definición previa de obligaciones de forma operativa (atender, ordenar y limpiar) y c) la regulación de ciclos de repetición que en el comercio, podrían observarse a lo largo de la jornada en las tareas obligatorias de limpieza y orden antes (apertura) y después (cierre) del establecimiento. Es así que, sobre el control del tiempo se establecen ritmos, se definen obligaciones y se regulan los "ciclos de repetición", con el objetivo de eliminar el tiempo "inútil", el tiempo muerto.

Para asegurar el logro de un tiempo bien aprovechado (útil), coordinado y sin obstáculos, los empleadores habitualmente registran y controlan personalmente, el desempeño general de trabajo de sus empleados y empleadas, cuando no pueden hacerlo, son tareas derivadas a las personas que se encargan del control del establecimiento general o bien, a las personas más experimentadas y con mayor antigüedad, sin embargo, también pueden hacerlo utilizando las cámaras de "seguridad". Quienes trabajan bajo estas condiciones se dan cuenta de estos hechos cuando los empleadores los interpelan si se demoran en regresar del baño, de almorzar o merendar o bien, si están sentados por mucho tiempo, deben mostrarse "siempre listos, predispuestos y activos" bajo cámara:

“(...) nosotras tenemos cámaras con audio y empezó a ser muy invasivo porque que pasa, al principio decís 'Ah seguridad' 'Para que no roben' 'Porque hay mucha gente.' No, no fue por eso, yo me di cuenta que fue para controlar para ver en qué minuto llegamos, en qué minuto nos vamos, qué hablamos, cuándo nos sentamos, cuánto tiempo estamos con el teléfono, que dejamos suelto y eso ya fue un punto... incluso me calmé, yo estuve alterada este tiempo pero para mí que las cámaras no andan porque están 'así y ahora están así...no sé si andan o no pero me he calmado porque no están las cámaras y no hago las cosas mal tampoco...." (Rosa).

Y como señala Magdalena, los controles también tienden a una "criminalización" que genera desconfianza y nerviosismo entre los trabajadores y las trabajadoras: 
“(..) No las dejan sentarse, si van al baño tienen que ir y volver, las revisan... antes de entrar ellas tienen que decir todo lo que llevan puesto, hasta la ropa interior que llevan puesta, se los anota y cuando salen, tienen que mostrar el bolso, y cuando entran también. Y tienen que hasta decir cuánta plata llevan en la billetera. Eso es así, son varios locales que son así..." (Magdalena).

\section{La conflictividad}

Las características del trabajo y las formas de control dan lugar al conflicto. Un conflicto indica la presencia de intereses contrapuestos entre quienes trabajan y quienes compran ese trabajo como expresión del antagonismo entre capital y trabajo. La "dinámica del conflicto" se configura a partir de las acciones y/o estrategias de resistencia emprendidas por las personas trabajadoras frente al control del proceso de trabajo por parte de los empleadores. Se identifican de esta forma dos grupos de conflictos: los de tipo salarial y de actividad.

a)Los conflictos salariales

Los que se asocian con la cuestión salarial se definen como conflictos por el pago de horas extra, paga doble, aumentos de sueldo o pago a término. Estos conflictos salariales no se enfocan en la situación de registro, sino en el pago "justo" según las horas trabajadas en base a su poder de compra. Carmen, por ejemplo, señala que, a los 6 meses de trabajar jornada completa en el mismo lugar, sólo percibía un salario por media jornada:

“(..) los primeros meses fueron terribles, yo justamente vivía sola en otro lugar, llegué a un punto en que no tenía ni para comer la verdad, terrible. Estaba flaca en ese momento, una desgracia, terrible hasta que yo no di más y agarré y llamé al contador que manejaba eso y le dije: 'mira, disculpame pero yo por este precio no trabajo..." (Carmen).

A los ya mencionados conflictos, pueden agregarse episodios de maltrato (gritos, insultos, acosos) y de manipulación (amenazas y "engaños"), donde esas situaciones también se observan más allá de las disputas salariales y habitualmente se expresan en la ejecución cotidiana de tareas y actividades. Dichos, conflictos, son denominados como conflictos de actividad y son los más usuales. Ramona destaca:

“(...) es muy vulgar para hablar (...) hay a veces que le sale el 'pelotuda' de la boca. (...) no te grita. A vece sí levanta la voz, pero no grita. Pero te trata de pelotuda, de que sos abriboca, de que personas asíno le sirven, tienen que ser más despiertas" (Ramona). 
b) Los conflictos de actividad

Los conflictos que transcurren a la actividad, surgen frente a la negativa de los empleadores y las empleadoras de brindar "permisos extraordinarios" a los casos entrevistados para asistir a nacimientos y cumpleaños de hijos/as, reuniones con la familia y/o amigos en eventos especiales. Estos se asocian con situaciones en las que el trabajo interfiere negativamente sobre el ámbito extra-laboral, afectando de igual manera a las relaciones de trabajo, precarizándolos:

“(..) cuando nació mi hija no me quisieron dar el día, les tuve que pedir por favor que me den el día que por ley me corresponde, ya como que eran muchas cosas que iban sumando que no quería estar ahí. De un día para el otro no es que tuve una discusión con el dueño, pero me trató muy mal, le pedí por favor en frente de mis compañeros que no me gritara. Me equivoqué en una factura, vino y me preguntó porque me había equivocado, le dije: 'No me levantes la voz, no me grites fue un error humano, no fue a propósito, fue sin mala intención' y se lo tomó a mal, no es como te lo estoy diciendo... (...) $Y$ así fue como al mes me echaron, yo lo vi como una oportunidad, no como una desazón..." (Pablo).

Además de un impacto negativo sobre las relaciones (con familiares, amigos y/o parejas), el trabajo en el comercio también puede generar problemas de salud, por su intensidad y, en algunos casos, incumplimiento de condiciones mínimas de higiene y seguridad. Se destacan algunos casos con ataques de pánico (Mabel, Melisa) y síndrome de fatiga crónica (Diego). De esta forma, los conflictos pueden desplegarse en combinación, es decir, unos pueden ser disparadores de otros y aquellos que permanecían dormidos o relegados pueden reactivarse en una nueva situación de disputa. Por ello, es importante señalar aquellos momentos en el que los casos entrevistados pusieron límites, reflexionaron que esas situaciones eran intolerables y decidieron actuar, defenderse y luchar.

En los conflictos de tipo salarial, el límite está dado por la insuficiencia del salario para acceder a bienes y servicios básicos y en los de actividad, las situaciones de maltrato y acoso, resultan determinantes para negarse a que continúen esos episodios junto con la interferencia del empleo fuera del ámbito laboral.

En conjunto, cada episodio irá definiendo, formando y perfeccionando las formas en que los y las jóvenes disputarán los problemas en el trabajo a futuro. Los casos entrevistados, frente a un conflicto intentan, en un primer momento, llegar a un acuerdo. La elección de las estrategias de resistencia que más acuerden con sus intereses dependerá de la importancia que le asignen a las situaciones de conflicto en tanto límites y del "margen de maniobra" disponible que durante el conflicto incluyan como riesgos y posibilidades de éxito en la adopción de alguna estrategia de 
resistencia siendo recurrente la identificación de riesgos en relación a la visibilidad y la variedad (posibilidad) de recursos empleados.

\section{c) Las resistencias}

Los conflictos señalados cuestionan la legitimidad y consenso otorgado al contrato de trabajo en términos globales. Se asocian al incumplimiento de expectativas en tanto necesidades económicas y de sus exigencias derivadas como límites: la contraprestación salarial, la realización de tareas, la dedicación horaria, por ejemplo. Como ya fue mencionado, en primer lugar, los casos entrevistados intentan dialogar con sus empleadores; plantear su problema y posibles soluciones. En algunos casos, existe apertura, diálogo y el conflicto desaparece, al negociar entre las partes un acuerdo beneficioso para ambos;

“(...) el otro día por el tema de las horas, nos parecía muy bajo el pago de las horas y se lo planteamos y le dijimos y lo modificaron este mes, pero porque te digo que hay buena predisposición de ellas -empleadoras-, no pasa en todos los lugares" (Mabel).

En los casos donde no existe diálogo, quienes emplean son inflexibles para responder a los reclamos y los casos entrevistados ceden para conservar su empleo, como se destacó anteriormente, el salario es un obrador de sentido para legitimar el contrato global celebrado incluso a sabiendas de que se asume por parte de los trabajadores y las trabajadoras una posición precaria en el empleo. La necesidad económica ocupa aquí un papel importante para explicar por qué los casos entrevistados deciden seguir vinculados a un empleo con estas características, donde al mismo tiempo esta situación opera como elemento de coacción, tal como sucede con Pablo:

“(..) por ahí creen que te están haciendo un favor al darte el laburo (...) 'acuérdese que lo pusimos en blanco' esa es la frase que te dicen y 'usted no puede exigir mucho acá... cuando les pedí que me pagaran las horas extras. La respuesta que les di: 'Yo no estoy acá porque le estoy pidiendo un favor, le estoy pidiendo lo que corresponde” (Pablo).

Luego del reclamo y la negativa de solución por la contraparte, el contrato general celebrado pierde legitimidad, el consenso inicial se debilita, dando lugar a las siguientes situaciones:

"La verdad que me empecé a frustrar mucho, estaba frustrado todo el día, trataba de estar bien en mi casa pero las ganas de trabajar no eran las mismas obviamente, me empezó a chupar un huevo las cosas, no te digo de faltar al laburo, empezar a fallar, no poerle pilas, llegar, cumplir horario, si llegamos bien y sino no importa" (Pablo). 
"Yo la única vez que deje que me influenciara el trabajo fue allá por culpa de ellos, no le iba a mostrar buena cara ni loca, los empecé a tratar muy mal... no a faltarles el respeto, pero no los saludaba, no aceptaba que me digan cosas de más, no atendía el teléfono, te lo juro, pero porque era culpa de ellos, era mi forma de vengarme porque me sentía mal" (Rosa).

Estos aspectos definen la emergencia de las resistencias "no tradicionales" o bien nuevas resistencias, a partir de expresiones de simulación que disfrazan el sentido de la disciplina (reglas y normas) -falso discurso, ironía, escepticismo y cinismo- y de fuga: ausentismo, trabajar lento, menos cooperación, desobediencia; tal como se observa en los relatos de entrevista. Lo que tienen en común es su baja exposición en términos de visibilidad ante los empleadores y las empleadoras y esto puede explicarse en términos de coacción económica, ya que el objetivo es sostener la fuente de trabajo, por ello estas expresiones no se despliegan como una confrontación abierta, son resistencias que transcurren individualmente y su efectividad, en términos de resolución del conflicto, es nula. A pesar de ello, manifiestan la presencia del conflicto y a la no inmovilización por parte de los trabajadores y las trabajadoras al reducir su cooperación en el establecimiento.

Ahora bien, entre los casos entrevistados, cuando los límites cuestionan el ejercicio coercitivo por necesidad desplegado por los empleadores y las empleadoras la legitimidad del arreglo conforme a la situación de registro, retribuciones y actividades pierde todo el consenso otorgado. Esto manifiesta un quiebre en la relación de trabajo y es allí donde se reconocen a las resistencias tradicionales como una vía posible de resolución:

“(...) Por ejemplo en mí caso, yo estaba en negro acá, con mi jefe estuve años así, hasta que un día lo senté y le dije: 'o te denuncio al Ministerio de Trabajo y me pagás lo que se debe o vos ves', entonces, ¿qué hizo él?, arregló conmigo particular, arreglarme a mí, pagarme a mí lo que a mí me corresponde y a mis compañeras les sigue pagando lo que les paga, ¿por qué?, porque si yo voy al Ministerio de Trabajo y yo denuncio, vienen, entran, investigan que están todas en las mismas situación y a todas les tiene que blanquear el sueldo $y$ depositarle" (Magdalena).

Las resistencias tradicionales implican entonces un mayor nivel visibilidad por los recursos que se resuelven utilizar (paro, escrache y manifestaciones públicas y denuncias ante sindicatos o dependencias estatales), haciendo que la confrontación directa aumente la posibilidad de perder el empleo. De esta forma las resistencias tradicionales suelen ser, según destacan los casos entrevistados, acciones y estrategias que se utilizan en última instancia, cuando la relación de trabajo y los términos convenidos en tanto registro, remuneraciones y actividades ya no cumplen con sus expectativas. 
Debe destacarse además que las resistencias tradicionales observadas no implicaron el apoyo colectivo (visible) de sus compañeros y compañeras de trabajo aunque si su apoyo tácito, aspecto que se destaca también en el ejercicio de las resistencias no tradicionales: antes de continuar con una acción, la consulta y opinión de compañeros y compañeras de trabajo es importante, ya que busca apoyo (aunque sea implícito) para lograr seguridad en el planteo del conflicto e incluso determinar la elección de estrategias más efectivas conforme a sus intereses.

"Si, nosotros por ejemplo en este local en particular, si tenemos un problema lo planteamos siempre, primero con mis pares y después lo planteamos con las dueñas" (Mabel).

“(...) todas tenemos el mismo sentimiento, eso es lo bueno, que todas tenemos relación, nos juntamos y tenemos... siempre hablamos los problemas entre nosotras. Siempre hablamos internamente" (Amanda).

Pero al mismo tiempo, el no apoyo en términos de visibilidad se posiciona como otro elemento compartido, como señala Clara "nadie dice nada...nadie dice me trataste mal o nadie se queja." O Mabel "No existe alguien que se haya puesto una bandera: 'No, che yo voy a pelear para que las cosas se mejoren para todos, síganme...' o cosas así no".

\section{Conclusiones}

A partir de los relatos de entrevista, la configuración de los comercios en el que los trabajadores y las trabajadoras jóvenes se encuentran vinculados destacan entre sus principales características la presencia de establecimientos de medianas y pequeñas superficies definiéndose como micro y pequeñas empresas de hasta 23 empleados. En su organización se destaca la presencia de capitales locales con participación directa en el trabajo cotidiano de los empleadores y las empleadoras (dueños y/o parientes directos) donde no existe un gerenciamiento profesional de la propuesta de negocios. Esto caracteriza a las propuestas comerciales en una dirección "más intuitiva" de la estrategia de negocio dirigida a fortalecer la relación con los clientes en función de su proximidad espacial; lo que se observa también en términos de selección de perfiles, organización administrativa y control.

Entre los criterios valorados para la selección de trabajadores y trabajadoras se destaca la disponibilidad horaria y responsabilidad en el cumplimiento en tanto horas y en la ejecución de las tareas y actividades asignadas. Los aspectos asociados a la calificación pasan a un segundo plano. En este sentido se observa cierta disposición por parte de los empleadores y las empleadoras, a partir del relato de las entrevistas a jóvenes, a formar a las personas en ese empleo. 
En términos de organización administrativa la presencia de profesionales en la gestión de algunas de las áreas de negocio no es frecuente con excepciones eventuales en la participación de contadores. Lo mismo sucede en la organización de las jerarquías internas en el establecimiento donde no se observan mandos medios de forma clara aunque, de manera informal, los trabajadores y las trabajadoras con mayor antigüedad y por lo tanto con mayores responsabilidades asumen una suerte de representante de sus empleadores y empleadoras en las tareas de organización y control de desempeño.

Este conjunto de características hace que los procedimientos de control sobre el desempeño sean dirigidos a sostener un registro estricto del tiempo en la ejecución de las tareas, actividades y su efectivo desarrollo que combina disponibilidad horaria, emocional y cognitiva. En la disponibilidad horaria como se señala en la caracterización del despliegue de tareas y actividades, la extensión de la jornada de trabajo, la disponibilidad de presentarse en el establecimiento fuera del día pactado previamente (flexibilidad) se combina con las exigencias emocionales y cognitivas en tanto se pretende la realización del acto de atención al cliente de forma enérgica, comprometida, responsable y con involucramiento individual, algo también señalado como exigencia por parte de los clientes según lo que manifiestan los y las jóvenes en entrevistas.

La diversidad de situaciones de registro (registro pleno, registro parcial y no registro) junto con los bajos salarios y la extensión paulatina de tareas respecto de la actividad principal (atención al cliente) que incrementan su intensidad conforme a las necesidades de los establecimientos durante días especiales, terminan por constituir un ámbito de trabajo con expresiones de precariedad laboral en diferentes intensidades, siendo aquellos casos no registrados los que en peores condiciones se encuentran. Aquí también toman un papel importante las realidades y necesidades económicas de las juventudes entrevistadas, siendo sus expectativas parcialmente diferentes entre quienes se ven en la responsabilidad de sostener a sus familias de origen o las propias y aquellos que destinan sus remuneraciones a complementar parte de sus consumos sin tener que contribuir a sus familias de origen influyendo en la elección del tipo jornada.

En ambos grupos, el salario se posiciona como uno de los elementos que terminan por definir la aceptación de los y las jóvenes trabajadoras para vincularse al empleo conociendo incluso las condiciones precarias de contratación. Es por ello que la necesidad económica se constituye como uno de los principales elementos de coacción por parte de los y las empleadoras. Si bien, el discurso por parte de los empleadores y las empleadoras se dirige a fortalecer el esfuerzo y la responsabilidad individual como elemento de cohesión o bien principio de consenso para el desarrollo de la actividad laboral sin obstáculos ni conflictos. Es recurrente la presentación pragmática sobre la situación y condición de inestabilidad en el trabajo, donde la posibilidad de perder 
el empleo resulta una de las respuestas señaladas por los casos entrevistados ante la emergencia de un conflicto en el trabajo, siendo frecuente entre los casos que se encuentran en una situación de precariedad más intensa como aquellos no registrados o parcialmente registrados.

Por otro lado, los conflictos en el trabajo se organizan como resultantes de la dimensión salarial o de actividad con reclamos que van desde el pago de horas extra, respeto de la extensión de la jornada acordada, episodios de maltrato y permisos extraordinarios denegados. Las formas de resolución iniciales, son de carácter individual y cuentan al diálogo como una primera estrategia que en los casos de negativa dan lugar a la emergencia de las resistencias no tradicionales o nuevas resistencias.

Estas resistencias no se plantean en términos de lucha de clases sino que se reducen a responder a un conflicto particular en el trabajo, como fue señalado, son en general emprendidas de forma individual y no buscan una confrontación directa (visible) a los empleadores y las empleadoras, sino más bien transcurren solapadas y ocultas. La visibilización (exposición) en términos tradicionales durante el planteo del conflicto como por ejemplo, un escrache o manifestación pública, mediante una denuncia ante las autoridades laborales o sindicato aumenta el riesgo a perder el empleo y por ello no es una alternativa viable ya que dichas instituciones no pueden asegurar su continuidad.

Por otro lado, con el despliegue de las estrategias y acciones de resistencia no tradicionales (nuevas resistencias de simulación y fuga), los casos entrevistados no consiguen transformar sus condiciones de trabajo aunque mantienen latentes los motivos de conflicto. Se afirma entonces el supuesto inicial de que las juventudes trabajadoras sostienen una lucha permanente en pos de mejorar sus condiciones de trabajo, expresándose en nuevas formas de resistencia sin conseguir mejoras en sus condiciones de trabajo, sin embargo estas situaciones continúan el debate en torno a la efectividad de las estrategias y acciones de resistencia junto al papel de los sindicatos.

Se lograron exponer las principales razones a partir del relato de las entrevistas en la elección de la construcción de alternativas de lucha (resistencias) reflejando al mismo tiempo las contradicciones en las que las juventudes trabajadoras se enfrentan en cada situación. En términos generales, sacrifica efectividad por continuidad laboral, es decir, no se recurre al sindicato o a las autoridades laborales para realizar una denuncia que compromete legalmente a los empleadores y empleadoras a responder en una instancia que demanda algún tipo de resolución puntual, sino que se opta por estrategias solapadas, invisibles, por las nuevas resistencias.

Lo anterior no quiere decir que las resistencias tradicionales sean desechables sino que a partir de los relatos de entrevista, estas estrategias y acciones resultan, en última instancia perjudiciales en términos de continuidad. Esto invita a repensar el papel de los sindicatos (máximos exponentes de las expresiones tradicionales de resistencia) 
como un problema que los interpela como organizaciones en un contexto de precariedad laboral en relación a la definición de nuevas estrategias y acciones de abordaje, sus relaciones con las empresas y el Estado, las limitaciones en torno a la legislación de trabajo y su vinculación con las poblaciones precarizadas y en particular con las juventudes, situaciones abordadas a nivel mundial y también en Argentina en el debate vigente sobre la revitalización sindical, donde los aportes de este trabajo pueden contribuir en algún punto.

Por otra parte, las expresiones de resistencia (tradicionales y nuevas resistencias) pueden re-pensarse en términos de subjetividades políticas, a fin de recuperar el desarrollo de las razones que motivan a la configuración de límites que atribuyen el quiebre y la emergencia de los conflictos, en los niveles de agregación de los mismos y sobre dinámicas de acompañamiento entre los compañeros y compañeras de trabajo. El debate sobre la formación de alternativas de carácter colectivo se extiende ampliamente en los estudios sobre militancia y participación política, siendo esta una apertura necesaria y novedosa, para las investigaciones que incluyan juventudes, sindicatos y precariedad.

\section{Referencias}

Abal Medina, Paula (2005). Condiciones de trabajo y representación sindical. Un estudio de caso en una empresa supermercadista. Red Académica para el Diálogo Social (s/d). Buenos Aires, Argentina.

Basualdo, Eduardo y Leandro Bona (2017). Capítulo V: La deuda externa (pública y privada) y la fuga de capitales durante la valorización financiera, 1976-2001. En E. Basualdo (ed.), Endeudar y fugar. Un análisis de la historia económica argentina, de Martínez de Hoz a Macri. (pp. 17-47). Buenos Aires: Siglo XXI Editores.

Beaud, Stéphane y Michel Pialoux (2009). Retorno a condicao operária. Investigacao em fábricas da Peugeot na Franca. Sao Paulo: Boitempo.

Bertranou, Fabio, Maribel Jiménez y Mónica Jiménez (2017). Trayectoria hacia el jóvenes en Argentina Trayectoria hacia el trabajo decente de los jóvenes en Argentina (Documentos de Trabajo No. 18, Oficina de). Buenos Aires: Oficina de País de la OIT para la Argentina.

Blousson, Alfredo (2009). La gestión del negocio minorista tradicional en la Argentina. Revista de instituciones, ideas y mercados, 50(1): 140-175.

Braverman, Harry (1974). Labor and Monopoly Capital The Degradation of Work in the Twentieth Century. New York: Monthly Review Press.

Brook, Paul (2009). In critical defence of 'emotional labour': refuting Bolton's critique of Hochschild's concept. Work, Employment and Society, 23(3): 531-548. Doi: https://doi.org/10.1177/0950017009337071. 
Burawoy, Michael (1979). Manufacturing Consent: Changes in the Labor Process under Monopoly Capitalism. The University of Chicago Press.

Castell, Manuel (2000). Globalización, sociedad y política en la era de la Información. Bitácora Urbano Territorial, 4(1), 42-53.

Cicellin, Mariavittoria, Mario Pezzillo Iacono, Alessia Berni y Vicenza Esposito (2015) Dealing with resistance in temporary agency nurses. Journal of Health Organization and Management, 29(3): 298-316. Doi: https://doi.org/10.1108/JHOM-022013-0044.

Collinson, Daniel (2003) Identities and insecurities: Selves at work. Organization, 10(3). 527-547. Doi: https://doi.org/10.1177/13505084030103010.

De la Garza Toledo, Enrique (2011). Trabajo no clásico, organización y acción colectiva. Ciudad de México: Plaza y Valdés.

De la Garza Toledo, Enrique (2018). La metodología configuracionista para la investigación social. Ciudad de México: Gedisa Editorial.

De la Garza Toledo, Enrique y Marcela Hernández (coord.) (2019). Configuraciones productivas y circulatorias en los servicios y trabajo no clásico. Recuperado de: http://www2.izt.uam.mx/sotraem/NovedadesEditoriales/ConfigTNC_Serv.pdf.

Ezzamel, Mahmoud y Hugh Willmott (2008). Strategy as discourse in a global retailer: A supplement to rationalist and interpretive accounts. Organization Studies, 29(2): 191-217. Doi: https://doi.org/10.1177/0170840607082226.

Favieri, Francisco (2018) Precariedad laboral multidimensional: algunos métodos multivariados de abordaje. En D. J Vejar (ed.) Precariedades del trabajo en América Latina (pp. 83-104). Santiago: RIL Editores - Ediciones UC de Temuco.

Fernández Milmanda, Belén (2010). Cuellos no tan blancos. Los trabajadores de supermercados y su desafío al viejo modelo sindical mercantil (Argentina 20042009). En V Congreso Latinoamericano de Ciencia Política. Buenos Aires: Acta Académica.

Fleming, Peter y Graham Sewell (2002). Looking for the Good Soldier, Svejk: Alternative Modalities of Resistance in the Contemporary Workplace. Sociology, 36(4): 857-873. Doi: https://doi.org/10.1177/003803850203600404.

Fleming, Peter (2005). Metaphors of resistance. Management Communication Quarterly, 19(1): 45-66. Doi: https://doi.org/10.1177/0893318905276559.

Grupo de Estudios sobre Sindicatos, Empresas y Trabajo (GESET) (2020) Boletín de coyuntura laboral de San Juan, (1): 1. Recuperado de https://drive.google.com/ open?id=1sfuSw39S1IsHCok3WCV6OHBcqLAh07uh

Bozkurt Ödül \& Irena Grugulis (2011). Introduction: why retail work demands a closer look en Retail Work (Critical Perspectives on Work and Employment) (pp. 1-21). London: Palgrave Macmillan. 
Groisman, Fernando y María Eugenia Sconfienza (2014). Una aproximación al desaliento laboral en Argentina. Cuadernos del Cendes, 31(87): 87-106.

Guiamet, Jaime (2017). Experiencias de la temporalidad del trabajo en una empresa multinacional de supermercados en la ciudad de Rosario. Revista Pilquen, 20(3): 56-66.

Hyman, Richard (1981). Relaciones industriales. Una introducción marxista. Madrid: Blume.

Ikeler, Peter. (2015). Deskilling emotional labour: evidence from department store retail. Work. Employment and Society, 30(6): 966-983. Doi: https://doi. org/10.1177/0950017015609031.

Jacinto, Claudia y Horacio Chitarroni (2010). Precariedades, rotación y movilidades en las trayectorias laborales juveniles. Revista Estudios del Trabajo, 39/40, 5-36.

Kosiak de Gesualdo, Graciela, Florencia Modesto, Belén Etchevarría y Gabriela Gesualdo (2015). Comercio minorista tradicional. Desafíos para su profesionalización. Revista de Ciencias Económicas, 11(1):41-56.

Longo, Julieta (2016). Temporalidades de los jóvenes en el trabajo. Sentidos del trabajo y experiencias del conflicto de empleados de empresas de supermercados durante la pos convertibilidad. Revista Theomai, 33(1): 101-122.

Lutgen-Sandvik, Paul (2006). Take this job and...: Quitting and other forms of resistance to workplace bullying. Communication Monographs, 73(4): 406-433. Doi: https://doi.org/10.1080/03637750601024156.

Marx, Carlos (2009a). El capital. Ciudad de México, México: Siglo XXI Editores.

Mason, Geoff y Mattew Osborne (2008). Business strategies, work organisation and low pay in United Kingdom retail. In: Lloyd C, Mason G and Mayhew K (eds.) Low Wage Work in the United Kingdom (pp. 131-68). New York: Russell Sage Foundation.

Maurizio, Roxana (2016). Formas atípicas de empleo en América Latina: incidencia, características e impactos en la determinación salarial. Serie condiciones de trabajo y empleo (76). Ginebra: OIT.

Mora Salas, Minor y Orlandia de Oliveira (2009). La degradación del empleo asalariado en los albores del siglo XXI: Costa Rica y México. Papeles de Población, 15(61): 195-231.

Neffa, Julio, Agustina Battistuzzi, Eugenio Biaffore y Andrea Suarez Maestre (2008). La informalidad, la precariedad laboral y el empleo no registrado en la provincia de Buenos Aires. Buenos Aires: CEIL-PIETTE-MTPBA.

Novick, Marta, Ximena Mazorra y Diego Schlesser (comp.) (2008). Aportes a una nueva visión de la informalidad laboral en la Argentina. Buenos Aires: Ministerio de Trabajo, Empleo y Seguridad Social (MTEySS) y Banco Mundial (BM). 
Nickson, Dennis, Robin Price, Hazel Baxter-Reid y Scott Hurrell (2016). Skill requirements in retail work: the case of high-end fashion retailing. Work, Employment and Society, 1(2): 1-17. Doi: https://doi.org/10.1177/0950017016672791.

Nickson, Dennis, Robin Price, Hazel Baxter-Reid, y Scott Hurrell (2011). Panorama laboral 2011. América Latina y el Caribe. Lima, Perú: Oficina Regional OIT para América Latina y el Caribe.

Nickson, Dennis, Robin Price, Hazel Baxter-Reid y Scott Hurrell (2013a). Análisis del mercado laboral juvenil. Un paquete de capacitación sobre información del mercado laboral juvenil. Ginebra, Suiza: Oficina Internacional del Trabajo-Departamento de Política de Empleo.

Nickson, Dennis, Robin Price, Hazel Baxter-Reid y Scott Hurrell (2013b). Trabajo decente y juventud en América Latina. OIT: Lima.

Nickson, Dennis, Robin Price, Hazel Baxter-Reid y Scott Hurrell (2014). Taller de validación de diagnóstico sobre cambios en la estructura social y productiva en Argentina. Desafios sindicales para CGT. Informa Final. OIT.

Nickson, Dennis, Robin Price, Hazel Baxter-Reid y Scott Hurrell (2015). Juventud y organizaciones sindicales en América Latina y el Caribe. OIT: Lima.

Nickson, Dennis, Robin Price, Hazel Baxter-Reid y Scott Hurrell (2019). Panorama Laboral 2019 América Latina y el Caribe. OIT: Lima.

Organización Internacional del Trabajo - Oficina de Actividades para los Trabajadores (OIT-ACTRAV) (2012). Del trabajo precario al trabajo decente. Documento final del simposio de los trabajadores sobre políticas y reglamentación para luchar contra el empleo precario. Ginebra: OIT.

Pastrana, Federico, Fernando Toledo y Soledad Villafañe (2012). Macroeconomía, Empleo e Ingresos. Debates y políticas en Argentina frente a la crisis internacional 2008-2009. Buenos Aires: Ministerio de Trabajo, Empleo y Seguridad Social (MTEySS) y Oficina de País de la OIT para la Argentina.

Pettinger, Lynne (2005). Gendered Work Meets Gendered Goods: Selling and Service in Clothing Retail. Gender, Work and Organization, 12(5): 460-478. Doi: https:// doi.org/10.1111/j.1468-0432.2005.00284.x.

Radiciotti, Luisina y Lucila D'Urso (2013). Heterogeneidad en el sector Comercio. Una mirada sobre las relaciones laborales en el subsector shopping center. En C. Senen González y A. Del Bono (eds.), La revitalización sindical en Argentina: alcances y perspectivas (pp. 171-192). Buenos Aires, Argentina: Consejo Latinoamericano de Ciencias Sociales (CLACSO).

Ruiz Olabuénaga, José (2003). Metodología de la investigación cualitativa. Málaga: Ediciones ALJIBE. 
Santamaría López, Elsa (2018). Jóvenes, crisis y precariedad laboral: una relación demasiado larga y estrecha. Encrucijadas. Revista Crítica de Ciencias Sociales, 15, $1-24$.

Scott, James (2000). Los dominados y el arte de la resistencia. México, Editorial Era.

Soria, Beatriz (2018). La dinámica del proceso de control-resistencias en los espacios de trabajo: aproximaciones a los debates clásicos y recientes. Sociológica, 33(94): 169-202.

Silver, Beverly (2005). Las fuerzas del trabajo. Los movimientos obreros y la globalización desde 1870. Madrid: Editorial Akal.

Stake, Robert (1995). Investigación con estudio de casos. Madrid: Morata.

Stecher, Antonio, Lorena Godoy y Juan Pablo Toro (2010). Condiciones y experiencias de trabajo en la sala de venta de un supermercado. Explorando los procesos de flexibilización laboral en el sector del retail en chile. POLIS, Revista Latinoamericana, 9(27):523-550.

Thompson Paul y Chris Smith (2009). Labour Power and Labour Process: Contesting the Marginality of the Sociology of Work. Sociology, 43 (5): 913-930.

Vargas, Eduardo (2019). Capitulo III: Hacia una configuración sociotécnica de la producción de viajes de los conductores de Uber. en E. De la Garza Toledo y M. Hernández (Coord.). Configuraciones productivas y circulatorias en los servicios y trabajo no clásico (pp. 60-86). Recuperado de: http://www2.izt.uam.mx/sotraem/ NovedadesEditoriales/ConfigTNC_Serv.pdf.

Williams, Christine y Catherine Connell (2010). Looking Good and Sounding Right: Aesthetic Labor and Social Inequality in the Retail Industry. Work and Occupations, 37(3): 349-377. Doi: https://doi.org/10.1177/0730888410373744.

Weller, Jurgen (2003). La problemática inserción laboral de los y las jóvenes. CEPAL: Santiago de Chile.

Weller, Jurgen (2006). Problemas de la inserción laboral de la población en América Latina. Papeles de población, 12(49): 9-36

Wyczykier, Gabriela (2012). Sindicalismo y precariedad laboral: un estudio sobre la acción gremial de base en la industria Argentina en el periodo de la postconvertibilidad. Estudios sociológicos, 30(89): 367-399.

Yin, Robert (1994). Case study research: design and methods. California: SAGE Publications. 


\section{Anexo}

Cuadro $\mathrm{N}^{\circ}$ 1: Jóvenes entrevistados según nombre ficticio, edad, departamento, antigüedad en el trabajo actual, características del establecimiento y nivel de instrucción. Gran San Juan. 3er trimestre de 2017.

\begin{tabular}{|c|c|c|c|c|c|c|}
\hline $\mathbf{N}^{\circ}$ & NF & Edad & $\begin{array}{l}\text { Departa- } \\
\text { mento }\end{array}$ & $\begin{array}{c}\text { Antigüe- } \\
\text { dad en el } \\
\text { trabajo } \\
\text { actual }\end{array}$ & $\begin{array}{l}\text { Características } \\
\text { del establec- } \\
\text { imiento }\end{array}$ & $\begin{array}{l}\text { Nivel de in- } \\
\text { strucción }\end{array}$ \\
\hline 1 & Clara & 23 & Capital & 6 meses & Librería & $\begin{array}{c}\text { Universitario } \\
\text { incompleto }\end{array}$ \\
\hline 2 & Mabel & 29 & Capital & 1 año & Ropa y calzado & $\begin{array}{c}\text { Universitario } \\
\text { incompleto }\end{array}$ \\
\hline 3 & Carmen & 25 & Capital & 8 meses & Librería & $\begin{array}{c}\text { Universitario } \\
\text { incompleto }\end{array}$ \\
\hline 4 & Pablo & 30 & Santa Lucía & 2 años & Distribuidora & $\begin{array}{c}\text { Universitario } \\
\text { incompleto }\end{array}$ \\
\hline 5 & Andrés & 26 & Rawson & $\begin{array}{c}1 \text { año y } 2 \\
\text { meses }\end{array}$ & Distribuidora & $\begin{array}{c}\text { Universitario } \\
\text { incompleto }\end{array}$ \\
\hline 6 & Melisa & 29 & Capital & 8 años & Ropa y calzado & $\begin{array}{l}\text { Terciario in- } \\
\text { completo }\end{array}$ \\
\hline 7 & Perla & 28 & Rivadavia & 5 meses & Ropa y calzado & $\begin{array}{c}\text { Universitario } \\
\text { incompleto }\end{array}$ \\
\hline 8 & Rosa & 22 & Rivadavia & $\begin{array}{c}2 \text { años y } 6 \\
\text { meses }\end{array}$ & Ropa y calzado & $\begin{array}{c}\text { Terciario in- } \\
\text { completo }\end{array}$ \\
\hline 9 & Alicia & 24 & Rivadavia & $1 \mathrm{mes}$ & Ropa y calzado & $\begin{array}{c}\text { Universitario } \\
\text { incompleto }\end{array}$ \\
\hline 10 & Verónica & 26 & Rivadavia & 6 meses & Heladería & $\begin{array}{c}\text { Universitario } \\
\text { incompleto }\end{array}$ \\
\hline 11 & Daniel & 25 & Capital & 4 años & Ropa y calzado & $\begin{array}{c}\text { Universitario } \\
\text { incompleto }\end{array}$ \\
\hline 12 & Pamela & 20 & Santa Lucía & 4 años & $\begin{array}{c}\text { Ramos gener- } \\
\text { ales }\end{array}$ & $\begin{array}{c}\text { Universitario } \\
\text { incompleto }\end{array}$ \\
\hline 13 & Amanda & 30 & Rivadavia & 6 años & Ropa y calzado & $\begin{array}{c}\text { Universitario } \\
\text { incompleto }\end{array}$ \\
\hline 14 & Ramona & 21 & Capital & $\begin{array}{c}1 \text { año y } 3 \\
\text { meses }\end{array}$ & Ropa y calzado & $\begin{array}{l}\text { Secundario } \\
\text { incompleto }\end{array}$ \\
\hline 15 & Diego & 30 & Capital & 3 años & $\begin{array}{c}\text { Electrodomés- } \\
\text { ticos }\end{array}$ & $\begin{array}{c}\text { Universitario } \\
\text { incompleto }\end{array}$ \\
\hline 16 & $\begin{array}{l}\text { Magda- } \\
\text { lena }\end{array}$ & 30 & Capital & 2 años & Ropa y calzado & $\begin{array}{c}\text { Secundario } \\
\text { completo }\end{array}$ \\
\hline
\end{tabular}




\begin{tabular}{|c|c|c|c|c|c|c|}
\hline 17 & Ricardo & 27 & Chimbas & 1 año & $\begin{array}{c}\text { Alimentos y } \\
\text { bebidas }\end{array}$ & $\begin{array}{c}\text { Universitario } \\
\text { incompleto }\end{array}$ \\
\hline 18 & Silvia & 23 & Capital & $\begin{array}{c}1 \text { año y } 8 \\
\text { meses }\end{array}$ & Ropa y calzado & $\begin{array}{c}\text { Universitario } \\
\text { incompleto }\end{array}$ \\
\hline 19 & Martina & 30 & Rivadavia & 8 meses & Ropa y calzado & $\begin{array}{c}\text { Secundario } \\
\text { completo }\end{array}$ \\
\hline
\end{tabular}

Fuente: Elaboración propia.

Cuadro $\mathrm{N}^{\circ}$ 2: Características de las empresas de los entrevistados según actividad, origen del capital, tamaño del local, relación interna entre negocios y locales y tipo de organización. Gran San Juan. 3er trimestre de 2017.

\begin{tabular}{|c|c|c|c|c|}
\hline Actividad & $\begin{array}{c}\text { Origen del } \\
\text { capital }\end{array}$ & $\begin{array}{c}\text { Tamaño } \\
\text { del local }\end{array}$ & $\begin{array}{c}\text { Relación } \\
\text { interna en- } \\
\text { tre negocios } \\
\text { y locales }\end{array}$ & $\begin{array}{c}\text { Tipo de organi- } \\
\text { zación }\end{array}$ \\
\hline $\begin{array}{c}1 \text { (Ropa y calzado) } \\
\text { y } 1 \text { (electrodomés- } \\
\text { ticos) }\end{array}$ & Nacional & $\begin{array}{c}\text { Grandes } \\
\text { superfi- } \\
\text { cies }\end{array}$ & Asociados & $\begin{array}{c}\text { Pública con un ger- } \\
\text { enciamiento profe- } \\
\text { sional }\end{array}$ \\
\hline $\begin{array}{c}1 \text { (Ropa y calzado) } \\
2 \text { (Librería), 2 (Dis- } \\
\text { tribuidora), 1 (He- } \\
\text { ladería), 1 (Ramos } \\
\text { generales), 9 (Ropa y } \\
\text { calzado), 1 (Alimen- } \\
\text { tos y bebidas) }\end{array}$ & -Franquicia & $\begin{array}{c}\text { Pequeñas } \\
\text { superfi- } \\
\text { cies }\end{array}$ & Asociados & $\begin{array}{c}\text { Familiar pero con un } \\
\text { gerenciamiento ter- } \\
\text { cerizado }\end{array}$ \\
\hline
\end{tabular}

Fuente: Elaboración propia en base características señaladas por Blousson (2009). 


\section{Sobre el autor}

Francisco Nicolás Favieri es licenciado y profesor en Sociología, Doctor en Ciencias Sociales. Becario posdoctoral del Consejo Nacional de Investigaciones Científicas y Técnicas (CONICET). Docente de Sociología Política y Sociología de la Población en el Departamento de Sociología, Facultad de Ciencias Sociales (FACSO), Universidad Nacional de San Juan (UNSJ). Es co-coordinador del Programa de Estudios e Investigaciones en Trabajo (PIET) del Instituto de Investigaciones Socio-Económicas (IISE) de la Universidad Nacional de San Juan (UNSJ). Estudia temáticas relacionadas al mercado de trabajo, juventudes, conflictividad laboral, sindicalismo y militancias. Correo electrónico: franciscofavieri@gmail.com. (D) http://orcid.org/0000-0002-61050461 


\title{
CUHSO
}

Fundada en 1984, la revista CUHSO es una de las publicaciones periódicas más antiguas en ciencias sociales y humanidades del sur de Chile. Con una periodicidad semestral, recibe todo el año trabajos inéditos de las distintas disciplinas de las ciencias sociales y las humanidades especializadas en el estudio y comprensión de la diversidad sociocultural, especialmente de las sociedades latinoamericanas y sus tensiones producto de la herencia colonial, la modernidad y la globalización. En este sentido, la revista valora tanto el rigor como la pluralidad teórica, epistemológica y metodológica de los trabajos.

\author{
EDITOR \\ Matthias Gloël \\ COORDINADORA EDITORIAL \\ Claudia Campos Letelier \\ CORRECTOR DE ESTILO Y DISEÑADOR \\ Ediciones Silsag \\ TRADUCTOR, CORRECTOR LENGUA INGLESA \\ Aurora Sambolin Santiago \\ SITIO WEB \\ cuhso.uct.cl \\ E-MAIL \\ cuhso@uct.cl \\ LICENCIA DE ESTE ARTÍCULO \\ Creative Commons Atribución Compartir Igual 4.0 Internacional
}

